\title{
Kaspar Elm
}

\section{Vita regularis sine regula Bedeutung, Rechtsstellung und Selbstverständnis des mittelalterlichen und frühneuzeitlichen Semireligiosentums}

\section{I.}

Der 1716 verstorbene Franziskaner Hippolyte Hélyot gab seiner zwischen 1714 und 1716 in Paris erschienenen fünfbändigen Geschichte des Ordenswesens, die nach seinem Tode um drei weitere von seinem Mitbruder Maximilian Bullot redigierte Bände vermehrt, danach vielfach aufgelegt und in andere Sprachen übersetzt wurde, nicht etwa den naheliegenden Titel "Histoire des ordres religieux“. Er nannte sie vielmehr, sorgfältig unterscheidend, „Histoire des ordres monastiques, religieux et militaires et des congrégations séculières de l'un et l'autre sexe"1. Wenn man auch nur einen Band dieses monumentalen, im 19. Jahrhundert von Marie-Léandre Badiche zur Grundlage seines zwischen 1847 und 1859 erschienenen "Dictionnaire des ordres monastiques, religieux et militaires" gemachten Werkes in die Hand nimmt, wird man an die Enzyklopädie Jean-Lerond d'Alemberts und Denis Diderots, aber auch an die ein halbes Jahrhundert später von Martin Gerbert, dem Abt von St. Blasien, in Angriff genommene "Germania Sacra“ erinnert ${ }^{2}$. Mit ihrem Drang nach Klassifizierung und Kategorisierung erweisen

${ }^{1} \mathrm{H}$. Hélyot, Histoire des ordres monastiques, religieux et militaires et des congrégations séculières de l'un et l'autre sexe, qui ont esté establies jusqu'à present (Paris 1714-1719); Dtsch.: Ausführliche Geschichte aller geistlichen und weltlichen Kloster- und Ritterorden für beyderley Geschlecht (Leipzig 1756); Dictionnaire des ordres monastiques, religieux et militaires ou Histoire des ordres ... par le P. Hélyot mis en ordre alphabétique par M.-L. Badiche (Encyclopédie théologique, I Série, T. XX-XXIII, Paris 1847-59). Über Hélyot, sein Werk, dessen Bearbeitungen und Verbreitung: I. Noye, Pierre Hélyot (en religion Hippolyte), in: Dictionnaire de Spiritualité VII (Paris 1969) $174 \mathrm{f}$.

2 J. Lough, The „Encyclopédie“ (London 1971); ders., The Contributors to the Encyclopédie (London 1973); M. Pichaut, L'Encyclopédie (Paris 1993). Über Gerbert zuletzt: L. Hell, Die eine Theologie und ihre Teile. Martin Gerberts Beitrag zur Geschichte der Theologischen Enzyklopädie, in: Freiburger Diözesan-Archiv 114 (1994) 7-34. Über sein Leben und seine Werke: W. Müller, Martin Gerbert. Fürstabt von St. Blasien 1720-1793, in: Lebensbilder aus Schwaben und Franken 12, hrsg. von $R$. Ubland (Stuttgart 1972) 100-120. Zur „Germania 
sich die Ordenshistoriker des 18. Jahrhunderts nicht nur als Exponenten spätbarocker Universalgelehrsamkeit bzw. aufklärerischen Systematisierungswillens ${ }^{3}$, sondern auch als Fortsetzer einer bis in die Frühzeit des Christentums, ja bis in die Antike zurückgehenden Tradition ${ }^{4}$. Die Gliederung nach genera und coetus, nach der contemplatio oder actio, der vita communis oder vita solitaria ${ }^{5}$, später nach Regel und Rechtsstellung gilt bis in die Gegenwart als die angemessenste Art und Weise, die sich im Laufe der Geschichte in eine unübersehbare Fülle von Lebensformen und Institutionen auffächernde vita religiosa zu klassifizieren 6 . Hélyot, Gerbert und jüngere Ordenshistoriker wie Max Heimbucher, erst recht aber die Geschichts- und Ordenstheologen des hohen Mittelalters gingen davon aus, daß sich die Prinzipien, die dieser Kategorisierung zugrunde liegen, aus dem Wesen der als göttliche Stiftung verstandenen Kirche, dem Ablauf der Heilsgeschichte und nicht zuletzt aus der religiösen Grundbefindlichkeit des Menschen ergäben, also ekklesiologisch, geschichtstheologisch und anthropologisch begründet

Sacra": G. Pfeilschiffer, Die St. Blasianische Germania Sacra (Münchener Studien zur historischen Theologie 1, Kempten 1921); L. Hammermayer, Die Forschungszentren der deutschen Benediktiner und ihre Vorhaben, in: Historische Forschung im 18. Jahrhundert. Organisation-Zielsetzung - Ergebnisse, 12. Deutsch-Französisches Historikerkolloquium des Deutschen Historischen Instituts Paris, hrsg. von K. Hammer, J. Voss (Pariser Historische Studien 13, Bonn 1976) 122-191.

${ }^{3} E$. W. Cochrane, The Settecento Medievalists, in: Journal of the History of Ideas 19 (1958) 36-61; L. Gossman, Medievalism and the Ideologies of Enlightenment (Baltimore 1968).

${ }^{4}$ Vgl. dazu u.a.: J. Joly, Le thème philosophique des genres de vie dans l'antiquité classique (Brüssel 1956); U. Ranke-Heinemann, Das Motiv der Nachfolge im frühen Mönchtum, in: Erbe und Auftrag 36 (1960) 335-347; G. Penco, Il capitolo „De generibus monachorum“ nella tradizione medievale, in: Studia monastica 3 (1961) 241-251.

5 M. E. Mason, Active Life and Contemplative Life. A Study of the Concepts from Plato to the Present (Milwaukee 1961); G. Turbesi, La solitudine come espressione ideale della vocazione cristiana, in: Benedictina 8 (1954) 43-56; G. Lobrichon, Erémitisme et solitude, in: Monteluco e i Monti Sacri. Atti dell'incontro di studio Spoleto, 30 settembre - 2 ottobre 1993 (Centro italiano di studi sull'Alto Medievo. Miscellanea 8, Spoleto 1994) 125-148; M.-E. Brunert, Das Ideal der Wüstenaskese und seine Rezeption in Gallien bis zum Ende des 6. Jahrhunderts (Beiträge zur Geschichte des Alten Mönchtums und des Benediktinertums 42, Münster 1994); H. J. Derda, Vita communis. Studien zur Geschichte einer Lebensform in Mittelalter und Neuzeit (Köln, Weimar, Wien 1992); K. Elm, Die Bedeutung historischer Legitimation für Entstehung, Funktion und Bestand des mittelalterlichen Ordenswesens, in: Herkunft und Ursprung. Historische und mythische Formen der Legitimation. Akten des Gerda-Henkel-Kolloquiums veranstaltet vom Forschungsinstitut für Mittelalter und Renaissance der Heinrich-Heine-Universität Düsseldorf, 13. bis 15. Oktober 1991, hrsg. von P. Wunderli (Sigmaringen 1994) 71-90.

6 Vgl. u.a.: J. Hourlier, Les religieux (Histoire du Droit et des Institutions de l'Église en Occident publié sous la direction de Gabriel Le Bras X: L’âge classique 1140-1378, Paris 1974); $R$. Lemoine, Le monde des religieux (ebd. XV/2: L'époque moderne 1563-1789, Paris 1976). Weitere Literatur: K. Elm, Orden I: Begriff und Geschichte des Ordenswesens, in: Theologische Realenzyklopädie XXV (Berlin 1995) 315-330; G. Melville, „Diversa sunt monasteria et diversas habent institutiones“. Aspetti delle moltiplici forme organizzative dei religiosi nel Medioevo, in: Chiesa e società in Sicilia. I secoli XII-XVI, hrsg. von G. Zito ( $\mathrm{Tu}$ rin 1995) 323-345. 
seien 7 . Erst die inzwischen weitgehend akzeptierte Auffassung, daß es sich bei der Entstehung des Asketen- und Mönchtums, erst recht aber bei der Ausbildung des Ordenswesens um einen von vielen Faktoren bestimmten Prozeß handelt, schuf die Voraussetzung dafür, Geschichte und Struktur des Ordenswesens so zu verstehen, wie es dem hochkomplizierten sozialen System, als das es sich uns heute darstellt, angemessen ist ${ }^{8}$. Aus dieser Einsicht ergaben sich für die Ordensforschung wichtige Konsequenzen. Seit den zwanziger Jahren unseres Jahrhunderts hat sich die Ansicht durchgesetzt, daß Orden und Häresien nicht mehr wie bisher als eigenständige Größen behandelt und klassifiziert werden dürften, sondern zumindest vom historischen Standpunkt aus - als komplementär oder dialektisch aufeinander bezogene Erscheinungsformen eines einzigen Phänomens, nämlich der auf zahlreiche Faktoren zurückzuführenden "Religiösen Bewegungen“ zu verstehen seien'. In die gleiche Richtung weist eine andere, sich zunehmend verstärkende Tendenz, die die Definition der Orden als rechtlich und sozial scharf voneinander abgegrenzte Institutionen einer Revision unterzieht, die Vorstellung, das Religiosentum stelle neben dem Klerus und den Laien eine der unverbunden nebeneinander stehenden tragenden Säulen der Kirche dar, modifiziert, die Wandlungs-, Anpassungs- und Reformbereitschaft des Ordenswesens betont und auf die breiten Übergangszonen sowohl zwischen dem Säkular- und dem Regularkle-

7 M. Heimbucher, Die Orden und Kongregationen der katholischen Kirche I-II (Paderborn 31934); $H$. Silvestre, „Diversi sed non adversi“, in: Recherches de théologie ancienne et médiévale 31 (1964) 124-132; G. Constable, The Diversity of Religious Life and Acceptance of Social Pluralism in the Twelfth Century, in: History, Society and the Churches. Essays in Honour of Owen Chadwick, hrsg. von D. Beales, G. Best (Cambridge 1985) 29-47; W. Eberhard, Ansätze zur Bewältigung ideologischer Pluralität im 12. Jahrhundert, in: Historisches Jahrbuch 105 (1985) 353-387; J. Leclercq, Diversification et identité dans le monachisme au XIIe siècle, in: Studia monastica 28 (1986) 51-74.

8 Vgl. u.a.: G. Schmelzer, Religiöse Gruppen und sozialwissenschaftliche Typologie. Möglichkeiten der soziologischen Analyse religiöser Orden (Sozialwissenschaftliche Abhandlungen der Görres-Gesellschaft 3, Berlin 1979).

9 G. Volpi, Movimenti religiosi e sette ereticali nella società medioevale italiana (Florenz 1922) und $H$. Grundmann, Religiöse Bewegungen im Mittelalter. Untersuchungen über die geschichtlichen Zusammenhänge zwischen der Ketzerei, den Bettelorden und der religiösen Frauenbewegung im 12. und 13. Jahrhundert und über die geschichtlichen Grundlagen der deutschen Mystik (Historische Studien 267, Berlin 1935); ders., Neue Beiträge zur Geschichte der religiösen Bewegungen im Mittelalter, in: Archiv für Kulturgeschichte 37 (1955) 129-182, auch in: ders., Ausgewählte Aufsätze. Teil 1: Religiöse Bewegungen (Schriften der Monumenta Germaniae Historica 25,1, Stuttgart 1976) 38-92. Vgl. auch: $R$. Büchner, Religiösität, Spiritualismus, geistige Armut, Bildung: Herbert Grundmanns geistesgeschichtliche Studien, in: Innsbrucker Historische Studien 1 (1978) 239-251; M. Wehrli-Johns, Voraussetzungen und Perspektiven mittelalterlicher Laienfrömmigkeit seit Innozenz III. Eine Auseinandersetzung mit Herbert Grundmanns „Religiösen Bewegungen“, in: Mitteilungen des Instituts für Österreichische Geschichtsforschung 104 (1996) 286-309. Über den Charakter „Religiöser Bewegungen“: J. J. van Moolenbroek, Mouvements populaires, mouvements religieux au Moyen Age, in: Le Moyen Age 93 (1987) 249-253; K. Elm, Francescanesimo e movimenti religiosi del Duecento e Trecento. Osservazioni sulla continuità e il cambiamento di un problema storiografico, in: Gli studi francescani dal dopo guerra ad oggi, hrsg. von F. Santi (Spoleto 1993) 73-89. 
rus als auch zwischen den beiden geistlichen Ständen und der Welt der Laien hinweist ${ }^{10}$.

Diese den dynamischen Charakter der bisher eher als statisch strukturiert angesehenen Kirche und ihrer Orden betonende Richtung ist zweifellos eine Folge der in unserem Jahrhundert eingetretenen tiefgreifenden Veränderungen des Kirchenverständnisses und der kirchlichen Praxis ${ }^{11}$, nicht zuletzt der bereits Ende des 19. Jahrhunderts einsetzenden, sich in der Zwischenweltkriegszeit verstärkenden und auf dem II. Vatikanischen Konzil zu einem Höhepunkt gekommenen Aufwertung der Laien und ihrer Rolle in der Kirche ${ }^{12}$. Sie führte nicht nur zu einer intensiven Beschäftigung mit Laien- und Volksfrömmigkeit des Mittelalters ${ }^{13}$,

10 Vgl. z.B.: R. Kottje, Monastische Reform oder Reformen?, in: Monastische Reformen des neunten und zehnten Jahrhunderts, hrsg. von $R$. Kottje, $H$. Maurer (Vorträge und Forschungen 38, Sigmaringen 1989) 9-13; K. Schreiner, Dauer, Niedergang und Erneuerung klösterlicher Observanz im hoch- und spätmittelalterlichen Mönchtum. Krisen, Reform- und Institutionalisierungsprobleme in der Sicht und Deutung betroffener Zeitgenossen, in: Institutionen und Geschichte. Theologische Aspekte und hochmittelalterliche Befunde, hrsg. von G. Melville (Norm und Struktur 1, Köln, Weimar, Wien 1992) 1-24. Allgemein zu „Statik“ und "Wandel“ als Paradigmata der Mittelalterforschung und -deutung: O. G. Oexle, „Die Statik ist ein Grundzug des mittelalterlichen Bewußtseins.“ Die Wahrnehmung sozialen Wandels im Denken des Mittelalters und das Problem ihrer Deutung, in: Sozialer Wandel im Mittelalter. Wahrnehmungsformen, Erklärungsmuster, Regelungsmechanismen, hrsg. von J. Miethke, K. Schreiner (Sigmaringen 1994) 45-70.

11 K. Rabner, Strukturwandel der Kirche als Aufgabe und Chance (Freiburg 1972); H. U. von Balthasar, Kirchenerfahrung dieser Zeit, in: „Sentire ecclesiam“. Das Bewußtsein von der Kirche als gestaltende Kraft der Frömmigkeit. Festschrift für Hugo Rahner, hrsg. von J. Daniélou, H. Vorgrimler (Freiburg 1981) 743-768; World Catholicism in Transition, hrsg. von T. M. Gannon (New York, London 1988); J. W. O'Malley, Tradition und Transition. Historical Perspectives on Vatican II (Wilmington 1989).

$12 Y$.-M. Congar, Jalons pour une théologie du laïcat (Paris 1953), Dtsch.: Der Laie. Entwurf einer Theologie des Laientums (Stuttgart ${ }^{21957) ; ~ D i e ~ K i r c h e ~ d e r ~ L a i e n . ~ E i n e ~ W e i c h e n s t e l l u n g ~}$ des Konzils, hrsg. von $R$. Zerfass (Würzburg 1987); G. Spadolini, Coscienza laica e coscienza cattolica (Florenz 1988); L. Karrer, Aufbruch der Christen. Das Ende der klerikalen Kirche (München 1989). Über die neuen Akzentsetzungen in der Erforschung und Beurteilung des "Christlichen Mittelalters": J. van Engen, The Christian Middle Ages as a Historiographical Problem, in: The American Historical Review 91 (1986) 519-552.

13 Vgl. u.a.: I laici nella "Societas christiana" dei secoli XI e XIII. Atti della terza Settimana internazionale di studio Mendola, 21-27 agosto 1965 (Pubblicazioni dell'Università Cattolica del Sacro Cuore. Miscellanea del Centro di studi medioevali V, Mailand 1968); R. Manselli, La religion populaire au moyen âge. Problèmes de méthode et d'histoire (Montréal 1975); A. Vauchez, Les laïcs au Moyen-Age. Pratiques et expérience religieuse (Paris 1987), Dtsch.: Gottes vergessenes Volk. Laien im Mittelalter (Freiburg, Basel, Wien 1993); $K$. Schreiner, Laienfrömmigkeit - Frömmigkeit von Eliten oder Frömmigkeit des Volkes? Zur sozialen Verfaßtheit laikaler Frömmigkeitspraxis im späten Mittelalter, in: Laienfrömmigkeit im späten Mittelalter. Formen, Funktionen, politisch-soziale Zusammenhänge, hrsg. von K. Schreiner unter Mitarbeit von E. Müller-Luckner (Schriften des Historischen Kollegs, Kolloquien 20, München 1992) 1-78; P. Dinzelbacher, Zur Erforschung der Geschichte der Volksreligion. Einführung und Bibliographie, in: Volksreligion im hohen und späten Mittelalter, hrsg. von P. Dinzelbacher, D. R. Bauer (Quellen und Forschungen aus dem Gebiet der Geschichte NF 13, Paderborn, München, Wien, Zürich 1990) 79-125; R. W. Scribner, Volksglaube und Volksfrömmigkeit. Begriffe und Historiographie, in: Volksfrömmigkeit in der 
sondern rief auch stärker als bisher ins Bewußtsein, daß es längst vor dem Aufkommen von "Säkularinstituten“, „Gesellschaften des apostolischen Lebens" und „anderen Formen des geweihten Lebens“, die das nachkonziliare Kirchenrecht dem als „Institut des geweihten Lebens“ bezeichneten Religiosentum als gleichberechtigte Formen der vita Deo devota an die Seite stellt ${ }^{14}$, zahlreiche Vor-, Neben-, Übergangs- und Z wischenformen der vita religiosa gegeben hat, die von einzelnen Individuen als „Semireligiosen“, „Halbmönchen“, „laici religiosi“, „religiosi irregolari ed independenti“, „sich halb geistlich, halb weltlich gebenden Personen“ praktiziert wurden oder zur Bildung von "groupes informels“, „free religious associations“, „freien religiösen Vereinigungen“ und „religiösen Laiengemeinschaften mit klosterähnlicher Lebensführung" führten, was das Bild vom Ordenswesen als einer acies ordinata, einer wohlgeordneten Schlachtreihe, erheblich modifizierte ${ }^{15}$. Im folgenden soll versucht werden, wenigstens in groben $\mathrm{Zü}-$ gen die Bedeutung dieses noch kürzlich von Grado G. Merlo als ein eben erst von der Forschung wiederentdecktes Universum bezeichneten Semireligiosentums herauszuarbeiten, seine Rechtsstellung und sein Selbstverständnis darzustellen und nach der Rolle der vita regularis sine regula beim Übergang vom Spätmittelalter zu Reformation und Konfessionalisierung gefragt werden ${ }^{16}$.

frühen Neuzeit, hrsg. von H. Molitor, H. Smolinski (Katholisches Leben und Kirchenreform im Zeitalter der Glaubensspaltung 54, Münster 1994) 121-135.

14 Das Konzil und die Orden. Die Lehre des II. Vatikanischen Konzils über den Ordensstand mit einem ausführlichen Kommentar, hrsg. von K. Siepen, A. Scheuermann (Köln 1966); G. Jelich, Kirchliches Ordensverständnis im Wandel. Untersuchungen zum Ordensverständnis des Zweiten Vatikanischen Konzils (Erlanger Theologische Studien 49, Erlangen 1983); A. Boni, La vita religiosa nella struttura concettuale del nuovo Codice di Diritto Canonico, in: Antonianum 58 (1983) 523-627; G. Pollak, Der Aufbruch der Säkularinstitute und ihr theologischer Ort (Vallendar 1986); R. Henseler, Ordensrecht (Münsterische Kommentare zum CIC. Sonderausgabe, Essen 1987); $R$. Seboll, Ordensrecht. Kommentar zu den Kanones 573-746 des Codex Iuris Canonici (Frankfurt 1995).

15 Zuletzt: Les mouvances laïques des ordres religieux. Actes du III Colloque International du C.E.R.C.O.R., hrsg. von N. Bouter (Saint-Étienne 1996).

${ }^{16}$ G. G. Merlo, Eremitismo nel francescanesimo medievale, in: Eremitismo nel francescanesimo medievale. Atti del XVII Convegno Internazionale Assisi, 12-13-14 ottobre 1989 (Perugia 1991) 48: „Cellane, incarcerate, penitenti domestiche, eremite, recluse, ripentite, incluse sono le protagoniste di un universo che soltanto da alcuni anni la ricerca ha incominciato a far emergere." Der Verfasser dieses Beitrages hat sich bereits in Aufsätzen über: Die Stellung der Frau in Ordenswesen, Semireligiosentum und Häresie zur Zeit der hlg. Elisabeth, in: Sankt Elisabeth. Fürstin - Dienerin - Heilige. Aufsätze. Dokumentation. Katalog, hrsg. von der Philipps-Universität Marburg in Verbindung mit dem Hessischen Landesamt für geschichtliche Landeskunde (Sigmaringen 1981) 7-38; Die Bruderschaft vom gemeinsamen Leben. Eine geistliche Lebensform zwischen Kloster und Welt, Mittelalter und Neuzeit, in: Geert Grote en Moderne Devotie. Voordrachten gehouden tijdens het Geert Grote congres, Nijmegen 27-29 september 1984, hrsg. von J. Andriessen, B. Bange, A. G. Weiler (Middeleeuwse Studies 1, Nimwegen 1985) 470-496 und Die Spiritualität der geistlichen Ritterorden des Mittelalters. Forschungsstand und Forschungsprobleme, in: 'Militia Christi' e Crociata nei secoli XI-XIII. Atti della undecima Settimana internazionale di studio Mendola, 28 agosto - 1 settembre 1989 (Pubblicazioni dell'Università Cattolica del Sacro Cuore. Miscellanea del Centro di studi medioevali XXX, Mailand 1992) 475-578 um eine Beschreibung der 
Die religiösen Bewegungen des hohen und späten Mittelalters haben sich nicht nur in den traditionellen Formen der vita religiosa institutionalisiert, also neue Abteien, Stifte, Konvente, Kongregationen, Observanzen, Orden und Ordenszöten entstehen lassen. Die monastischen und kanonikalen Reformen sowie die Apostolische Armutsbewegung des 12., die Armuts-, Buß- und Eremitenbewegung des 13. und die für das 14. und 15. Jahrhundert charakteristischen Observanz- und Reformbestrebungen haben vielmehr neben neuen Formen des „eigentlichen“ Ordenslebens solche Lebens- und Gemeinschaftsformen hervorgebracht bzw. wiederbelebt, die es den Gläubigen, in erster Linie den Laien, erlaubten, auf Dauer oder vorübergehend ein geistliches Leben zu führen, das intensiver war als das von ihnen bisher geführte, sie aber dennoch nicht wie die Ordensleute verpflichtete, gänzlich der Welt zu entsagen, sich den bestehenden Orden pleno iure anzuschließen und nach approbierten Regeln und Konstitutionen zu leben ${ }^{17}$.

Eigenart, Rechtsstellung und Bedeutung des Semireligiosentums bemüht. Er schließt mit diesem Beitrag daran an, wobei er sich bewußt ist, daß für eine umfassende Darstellung dieser geistlichen Lebensform noch erhebliche Vorarbeit, vor allem auf dem Gebiet der Kanonistik und Rechtsgeschichte, zu leisten ist.

17 Aus der Literatur zur Geschichte der erwähnten religiösen Bewegungen des hohen und späten Mittelalters u.a.: F. A. Dal Pino, Rinnovamento monastico-clericale e movimenti religiosi evangelici nei secoli X-XII (Rom 1973); K. Bosl, Europa im Aufbruch: Herrschaft, Gesellschaft, Kultur vom 10. bis zum 14. Jahrhundert (München 1980); Renaissance and Renewal in the Twelfth Century, hrsg. von R. L. Benson, G. Constable, C. D. Lanham (Cambridge 1982); L'Europa dei secoli XI e XII fra novità e tradizione. Sviluppi di una cultura. Atti della decima Settimana internazionale di studio Mendola, 25-29 agosto 1986 (Pubblicazioni dell'Università Cattolica del Sacro Cuore. Miscellanea del Centro di studi medioevali XII, Mailand 1989); Aufbruch - Wandel - Erneuerung. Beiträge zur "Renaissance“ des 12. Jahrhunderts, hrsg. von G. Wieland (Stuttgart, Bad Cannstadt 1995). Darin besonders erwähnenswert: A. Haverkamp, Leben in Gemeinschaften - alte und neue Formen im 12. Jahrhundert, 11-44; P. Dinzelbacher, Die „Bernhardinische Epoche“ als Achsenzeit der europäischen Geschichte, in: Bernhard von Clairvaux und der Beginn der Moderne, hrsg. von $D$. $R$. Bauer, G. Fuchs (Innsbruck, Wien 1996) 9-46 mit Literaturhinweisen zum Thema (S. 47-53); Machtfülle des Papsttums 1054-1274, hrsg. von A. Vauchez, dtsch. Ausgabe bearbeitet von O. Engels u.a. (Die Geschichte des Christentums 5, Freiburg, Basel, Wien 1994); La conversione alla povertà nell'Italia dei secoli XII-XIV. Atti del XVIII Convegno storico internazionale Todi, 14-17 ottobre 1990 (Atti dei Convegni dell'Academia Tudertina e del Centro di studi sulla spiritualità medievale NS 4, Spoleto 1991), darin besonders aufschlußreich und mit zahlreichen Literaturhinweisen: F. Dal Pino, Scelte di povertà all'origine dei nuovi ordini religiosi dei secoli XII-XIV (53-126); Religiones novi (Quaderni di storia religiosa 2, Verona 1995); K. Elm, Verfall und Erneuerung des Ordenswesens im Spätmittelalter, in: Untersuchungen zu Kloster und Stift (Veröffentlichungen des Max-Planck-Instituts für Geschichte 68. Studien zur Germania Sacra 14, Göttingen 1980) 188-238; G. Zarri, Aspetti dello sviluppo degli ordini religiosi in Italia tra Quattro e Cinquecento. Studi e problemi, in: Strutture ecclesiastiche in Italia e Germania prima della Riforma, hrsg. von P. Prodi, P. Johanek (Annali del Istituto storico italo-germanico. Quaderno 16, Bologna 1984) 207-258; Reformbemühungen und Observanzbestrebungen im spätmittelalterlichen Ordenswesen, hrsg. von $K$. 
Die Erscheinungsformen der vita semireligiosa, die nach Alter und Zusammensetzung, Intentionen und Organisationsgrad, Kirchennähe und Kirchenferne, Selbstverständnis und Fremdbezeichnung nicht unerheblich voneinander abweichen, reichen von dem Inklusen-18, Konversen-19 und Donateninstitut ${ }^{20}$ über „Verbrüderungen" und unregulierte Mischformen „monastischen“ und „kanonikalen“, "geistlichen“ und „laikalen“ Lebens ${ }^{21}$ bis zu selbständigen Gemeinschaf-

Elm (Berliner Historische Studien 14, Ordensstudien VI, Berlin 1989); D. Mertens, Monastische Reformbewegungen des 15. Jahrhunderts: Ideen - Ziele - Resultate, in: Reform von Kirche und Reich zur Zeit der Konzilien von Konstanz (1414-1418) und Basel (1431-1449). Konstanz - Prager Historisches Kolloquium, 11.-17. Oktober 1993, hrsg. von I. Hlaváček, A. Patschovsky (Konstanz 1996) 157-181.

18 L. Gougard, Ermites et reclus. Études sur d'anciennes formes de vie religieuse (Moines et monastères V, Saint-Martin de Ligugé 1928); ders., Essai de bibliographie érémitique, in: Revue bénédictine 45 (1933) 281-290; O. Dörr, Das Institut der Inclusen in Süddeutschland (Beiträge zur Geschichte des Alten Mönchtums und des Benediktinerordens 18, Münster 1934); M. Le Roy Ladurie, Femmes au désert. Temoignage sur la vie érémitique (Paris, Fribourg 1971); J. Leclercq, Solitude and Solidarity. Medieval Women Recluses, in: Medieval Religious Women II. Peaceweavers, hrsg. von L. Th. Schank, J. A. Nichols (Kalamazoo 1987); G. Casagrande, Il fenomeno della reclusione volontaria nei secoli del Basso Medioevo, in: Benedictina 35 (1988) 504-507.

19 Beiträge zur Geschichte der Konversen im Mittelalter, hrsg. von K. Elm (Berliner Historische Studien 2, Ordensstudien I, Berlin 1980) mit Auswahlbibliographie zur Geschichte der Konversen im Mittelalter.

$20 \mathrm{~J}$. Orlandis, "Traditio corporis et animae“. Laicos y monasterios en la alta edad media española, in: Anuario de Historia del Derecho Español 24 (1954) 95-279; J. Marchel, Le "Droit d'oblat". Essai sur une variété de pensionnés monastiques (Archives de la France monastique 49,Saint-Martin de Ligugè 1955); J. Guilmard, Les oblats séculiers dans la famille de S. Benoît (Solesmes 1975); M. B. de Jong, Kind en klooster in de vroege middeleeuwen (Amsterdamsche Reeks 8, Amsterdam 1986); M. Labaye-Geussen, Das Opfer der Kinder. Ein Beitrag zur Liturgie- und Sozialgeschichte des Mönchtums im Hohen Mittelalter (Münsteraner Theologische Abhandlungen 13, Altenberge 1991); D. J. Osheim, Conversion, Conversi and the Christian Life in Late Medieval Tuscany, in: Speculum 58 (1983) 368-390; G. G. Merlo, Uomini e donne in communità 'estese'. Indagini su realtà piemontesi tra XII e XIII secolo, in: Uomini e donne in comunità (Quaderni di storia religiosa 1, Verona 1994) 9-31.

$21 \mathrm{~J}$. Wollasch, Die mittelalterliche Lebensform der Verbrüderung, in: Memoria. Der geschichtliche Zeugniswert des liturgischen Gedenkens im Mittelalter, hrsg. von $K$. Schmid, $J$. Wollasch (Münstersche Mittelalter-Schriften 48, München 1984) 215-232; H. E. Cowdrey, Legal Problems Raised by Agreements of Confraternity, ebd. 233-254. Zu den in diesem Zusammenhang besonders erwähnenswerten „semireligiosen“ Kanonissen, auf die $K .-H$. Schäfer, Die Kanonissenstifter im deutschen Mittelalter. Ihre Entwicklung und innere Einrichtung im Zusammenhang mit dem altchristlichen Sanktimonialentum (Kirchenrechtliche Abhandlungen 43-44, Stuttgart 1907, ND Amsterdam 1965) zuerst nachdrücklich hingewiesen hat, u.a.: G. Despy, Les chapitres de chanoinesses nobles de Belgique au Moyen Age, in: $36^{\circ}$ Congrès de la Fédération Archéologique et Historique de Belgique (Gent 1955) 169-179; I. Gampe, Adelige Damenstifte. Untersuchungen zur Entstehung adeliger Damenstifte in Österreich unter besonderer Berücksichtigung der alten Kanonissenstifte Deutschlands und Lothringens (Wiener Rechtsgeschichtliche Arbeiten, Wien, München 1960); M. Parisse, Les chanoinesses dans l'empire germanique (IXe-XIe siècles), in: Francia 6 (1978) 107-126; W. Kobl, Bemerkungen zur Typologie sächsischer Frauenklöster im westlichen Sachsen, in: Untersuchungen zu Kloster und Stift (Veröffentlichungen des Max-Planck-Instituts für Geschichte 68. Studien zur Germania Sacra 14, Göttingen 1980) 112-139 sowie J. E. Ziegler, 
ten von Laien und Klerikern, in denen ohne formelle Bindung und anerkannte Regel in brüderlicher Gemeinsamkeit Selbstheiligung gesucht, karitative Tätigkeit ausgeübt und geistliches Apostolat übernommen wurde 22 . Ja, man geht gelegentlich sogar so weit, ihnen nicht nur die kirchenrechtlich privilegierten Pilger und Kreuzfahrer, sondern auch die Sterbenden zuzurechnen, die auf dem Totenbett das Mönchsgewand anlegten, um im Jenseits der Verdienste des Mönchslebens teilhaftig zu werden ${ }^{23}$. Während zunächst die an Kloster und Stift gebundenen Institute dieser Art überwogen ${ }^{24}$, setzte im 12. Jahrhundert, dem Jahrhundert des großen Aufbruchs, mit der zunehmenden Gründung von Eremitorien ${ }^{25}$

Secular Canonesses as Antecedents of the Beguines in the Low Countries. An Introduction to Some Older Views, in: Studies in Medieval and Renaissance History NS 13 (1992) 117-135.

22 S. die Anm. 36 und 44.

${ }^{23} \mathrm{~F}$. Garrison, A propos des pèlerins et de leur condition juridique, in: Études d'histoire du droit canonique dédiées à G. Le Bras (Paris 1965) II, 1165-1189; G. B. Ladner, „Homo viator". Medieval Ideas on Alienation and Order, in: Speculum 42 (1967) 233-259; L. Schmugge, „Pilgerfahrt macht frei“. Eine These zur Bedeutung des mittelalterlichen Pilgerwesens, in: Römische Quartalsschrift 74 (1979) 31-75. M. Villey, La croisade. Essai sur la formation d'une théorie juridique (L'Église et l'État au Moyen Age 6, Paris 1942); J. Brundage, Medieval Canon Law and the Crusader (Madison, London, 1969). J. B. Valvekens, Fratres et Sorores „ad succurrendum“, in: Analecta Praemonstratensia 37 (1961) 323-328; U. Brückner, Sterben im Mönchsgewand. Zum Funktionswandel einer Totkleidsitte, in: Kontakte und Grenzen. Probleme der Volks-, Kultur- und Sozialforschung. Festschrift für G. Heilfurth (Würzburg 1969) 259-277.

24 U. Berlière, La Familia dans les monastères bénédictins du moyen âge (Memoires de l'Academie Royale de Belgique. Classe de Lettres et de Sciences morales et politiques XIX/2, Brüssel 1931). Zur „Familia“ einzelner Stifte und Klöster: $K$. Elm, Fratres et Sorores Sanctissimi Sepulcri. Ein Beitrag zu fraternitas, familia und weiblichem Religiosentum im Umkreis des Kapitels vom Hlg. Grab, in: Frühmittelalterliche Studien 9 (1975) 287-333; H. Dormeier, Montecassino und die Laien im 11. und 12. Jahrhundert. Mit einem einleitenden Beitrag: Zur Geschichte Montecassinos im 11. und 12. Jahrhundert von Hartmut Hoffmann (Schriften der Monumenta Germaniae Historica 27, Stuttgart 1979); M. de Jong, Kloosterlingen en buitenstaanders. Grensoverschrijdingen in Ekkehards Casus Sancti Galli, in: Bijdragen en mededelingen betreffende de geschiedenis der Nederlanden 98 (1983) 337-357; J. Fechter, Cluny, Adel und Volk. Studien über das Verhältnis des Klosters zu den Ständen (Stuttgart 1966); G. Constable, Famuli and Conversi at Cluny. A Note on Statute 24 of Peter the Venerable, in: Revue bénédictine 83 (1973) 326-350; W. Teske, Laien, Laienmönche und Laienbrüder in der Abtei Cluny. Ein Beitrag zum Konversenproblem, in: Frühmittelalterliche Studien 10 (1976) 248-322, 11 (1977) 288-339; J. Wollasch, Cluny - „Licht der Welt“. Aufstieg und Niedergang der klösterlichen Gemeinschaft (Zürich, Düsseldorf 1996) 101-140.

25 L'Eremitismo in Occidente nei secoli XI-XII. Atti della seconda Settimana internazionale di studi Mendola, 30 agosto-6 settembre 1962 (Pubblicazioni dell Università Cattolica del Sacro Cuore, Miscellanea del Centro di studi medioevali IV, Mailand 1965); H. Grundmann, Deutsche Eremiten. Einsiedler und Klausner im Hochmittelalter (10.-12. Jahrhundert), in: Archiv für Kulturgeschichte 45 (1963) 60-90. Auch in: ders., Ausgewählte Aufsätze (wie Anm. 9) I, 93-124; J. Sainsaulieu, Les ermites français (Sciences et religions, Paris 1974); A. $K$. Warren, Anachoretes and their Patrons in Medieval England (Berkeley, Los Angeles, London 1985); G. Penco, L'eremitismo irregolare in Italia nei secoli XI-XII, in: Benedictina 32 (1985) 201-221; G. Casagrande, Forme di vita religiosa femminile solitaria in Italia Centrale, in: Eremitismo nel francescanesimo (wie Anm. 16), 53-94; E. Pásztor, Ideali 
und Hospitälern ${ }^{26}$ eine Vermehrung der zwischen Orden und Welt stehenden Individuen und Gemeinschaften ein, die im 13. Jahrhundert mit Bußbrüderschaft ${ }^{27}$ und Drittordenswesen ${ }^{28}$ zu einem Höhepunkt kam und im Spätmittelalter mit Beginen und Begarden ${ }^{29}$, Brüdern und Schwestern vom Gemeinsamen Leben ${ }^{30}$

dell'eremitismo femminile in Europa tra i secoli XII-XV, in: ebd. 131-164; P. Gebrke, Pious Hermits and Magical Helpers. Alternative Solutions for Spiritual Problems, in: Saints and Scribes. Medieval Hagiography in its Manuscript Context (University of California Publications in Modern Philology 126, Berkeley, Los Angeles 1993) 86-104.

${ }^{26}$ Histoire des hôpitaux, hrsg. von J. Imbert (Toulouse 1982); D. Jetter, Das europäische Hospital. Von der Spätantike bis 1880 (Köln 1987); G. Castelli, Gli ospedali d'Italia (Mailand 1941); C. Dainton, The Story of the English Hospital (London 1961); P. Bonenfant, Hôpitaux et bienfaisance dans les anciens Pays-Bas des origines à la fin du XVIIIe siècle, in: Annales de la Société Belge d'Histoire des Hôpitaux 3 (1965) 1-44; G. Maréchal, Armen - en ziekenzorg in de zuidelijke Nederlanden, in: Algemene Geschiedenis der Nederlanden II (Harlem 1982) 268-280, 541; E. Gilomen-Schenkel, Spitäler und Spitalorden in der Schweiz. Ein Forschungsbericht, in: Die Antoniter, die Chorherren vom Hlg. Grab in Jerusalem und die Hospitaliter vom Hlg. Geist in der Schweiz, redigiert von E. Gilomen-Schenkel (Helvetia Sacra IV/4, Basel, Frankfurt a. M. 1996) 19-34. Speziell über den semireligiosen Charakter von Hospitalbrüdern und Hospitalschwestern: D. Rando: „Laicus religiosus“ tra strutture civili ed ecclesiastiche: L'ospedale di Ognisanti in Treviso, in: Studi Medievali 24 (1983) 617-656; Ch. de Miramon, Les donnes à Lille au Moyen Age. Une forme de vie religieuse laique, in: Revue du Nord 76 (1994) 231-253.

27 G. G. Meersseman, I penitenti nei secoli XI e XII, in: I laici (wie Anm. 13) 306-309. Auch in: ders., G. P. Pacini, Ordo Fraternitatis. Confraternite e pietà dei laici nel medioevo (Italia Sacra 24-26, Rom 1977) 265-304; G. Casagrande, Il movimento penitenziale nel Medio Evo, in: Benedictina 27 (1980) 695-709; G. Penco, Tra monachesimo e laicato: l'ordine dei Penitenti, in: ebd. 29 (1982) 489-494; G. Casagrande, Il movimento penitenziale nei secoli del Basso Medioevo. Note su alcuni recenti contributi, in: ebd. 30 (1983) 217-233.

28 Mit besonderer Betonung der Franziskanertertiaren unter Berücksichtigung auch der von anderen Orden betreuten Pönitenten bzw. Drittordensleuten: I Frati Penitenti di San Francesco nella società del Due e Trecento. Atti del $2^{\circ}$ Convegno di Studi Francescani Roma, 12-13-14 ottobre 1976, hrsg. von M. D'Alatri (Rom 1977); Il Movimento Francescano della Penitenza nella società medioevale. Atti del 30 Convegno di Studi Francescani Padova, 25-26-27 settembre 1979, hrsg. von M. D'Alatri (Rom 1980). I Frati Minori e il Terzo Ordine. Probleme e discussioni storiografiche (Convegno del Centro di studi sulla spiritualità medievale 23, Todi 1985); M. D'Alatri, Aetas poenitentialis. L'antico Ordine francescano della Penitenza (Bibliotheca Seraphico-Capuccina 42, Rom 1993). Eine knappe Zusammenfassung der bisherigen Ergebnisse der Tertiarenforschung gibt: G. Barone, Tertiarier, in: Lexikon des Mittelalters VIII (1996) 556-559.

${ }^{29}$ A. Mens, Orsprong en betekenis van de Nederlandse Begijnen - en Begardenbeweging. Vergelijkende studie: XIIde-XIIIde eeuw (Verhandelingen van de Koninklijke Vlaamse Academie voor Wetenschappen, Letteren en Schone Kunsten van België. Klasse der Letteren IX, 7, Antwerpen 1947); E. W. McDonell, The Beguines and Begards in Medieval Culture. With Special Emphasis on the Belgian Scene (New Brunswick N.J. 1954). Über den gegenwärtigen Stand der Erforschung und die heutige Einschätzung des Beginentums u.a.: W. Simon, The Beguine Movement in the Southern Low Countries: A Reassessment, in: Bulletin de l'Institut historique belge de Rome 59 (1989) 63-105.

30 Monasticon Fratrum Vitae Communis I-II, hrsg. von W. Leesch, E. Persoons, A. G. Weiler (Archives et bibliothèques de Belgique. Numéro spécial 18-19, Brüssel 1977/79); $A$. G. Weiler, Volgens de norm van de vroege kerk. De geschiedenis van de huizen van de broeders van het Gemene leven in Nederland (Middeleeuwse Studies XXIII, Nimwegen 1997); G. Rehm, 
sowie zahlreichen anderen vergleichbaren Zusammenschlüssen ein solches Ausmaß erreichte, daß die semireligiosen die religiosen Gemeinschaften quantitativ einholten ${ }^{31}$, wenn nicht gar überholten und ihre Lebensführung „tra status laicalis e status religiosus" 32 nicht mehr nur als eine marginale Form der vita religiosa hingenommen, sondern sowohl von Laien als auch von Klerikern als das höchste Ziel des Vollkommenheitsstrebens, „der hoechste grad, den die hailig cristenheid kennt", angesehen wurde ${ }^{33}$.

\section{III.}

Das sich seit dem 12. Jahrhundert allenthalben in Europa, vor allem in den Städten, aber auch in ländlichen Regionen, in einer kaum überschaubaren Vielfalt von Formen und unter heute nur schwer zu definierenden und eindeutig festzulegenden Bezeichnungen mit erstaunlicher Geschwindigkeit ausbreitende Semireligiosentum war für Kirche und Gesellschaft sowohl in geistiger als auch in materieller Hinsicht von kaum zu unterschätzender Bedeutung. Seine geringe Verbindlichkeit, der niedrige Organisationsgrad und die leichteren Eintrittsbedingungen boten Gläubigen beiderlei Geschlechts und verschiedener Herkunft die Möglichkeit, ihre religiösen Intentionen auch dann zu realisieren, wenn sie Überzeugung, soziale Stellung oder andere Gründe daran hinderten, in den Ordensstand einzutre$\operatorname{ten}^{34}$, und ihnen die Zugehörigkeit zu einer der weit verbreiteten "profanen“ Bru-

Die Schwestern vom gemeinsamen Leben im nordwestlichen Deutschland. Untersuchungen zur Geschichte der Devotio moderna und des weiblichen Religiosentums (Berliner Historische Studien 11, Ordensstudien V, Berlin 1985).

${ }^{31}$ Aus der Fülle der Arbeiten zur regionalen Verbreitung männlicher und weiblicher Semireligiosen seien exemplarisch die folgenden Arbeiten genannt, die trotz der einschränkenden und in gewissem Sinne irreführenden Formulierung ihrer Titel die Vielfalt vor allem weiblicher Semireligiosengemeinschaften am Beispiel Badens, der Schweiz und Mittelitaliens dokumentieren: $A$. Wilts, Beginen im Bodenseeraum (Bodensee-Bibliothek 37, Sigmaringen 1994); B. Degler-Spengler, Die Beginen im Rahmen der religiösen Frauenbewegung des 13. Jahrhunderts in der Schweiz, in: Die Beginen und die Begarden in der Schweiz (Helvetia Sacra IX, 2, Zürich 1995) 31-91; A. Benvenuti Papi, „In castro poenitentiae“. Santità e società femminile nell'Italia medievale (Italia Sacra 45, Rom 1990); M. Sensi, Storie di Bizzoche tra Umbria e Marche (Storia e letteratura. Raccolta di studi e testi 192, Rom 1995). Allgemein zum quantitativen Aspekt des weiblichen Religiosen- und Semireligiosentums: $B$. DeglerSpengler, Die religiöse Frauenbewegung des Mittelalters. Konversen - Nonnen - Beginen, in: Rottenberger Jahrbuch für Kirchengeschichte 3 (1984) 75-88.

32 Casagrande, Forme di vita religiosa (wie Anm. 25), 60.

33 Des Teufels Netz. Satirisch-didaktisches Gedicht aus der ersten Hälfte des fünfzehnten Jahrhunderts, hrsg. von K. A. Barack (Stuttgart 1863) 193-199. Über eine ähnlich positive Beurteilung der semireligiosen Frauen durch Robert Grosseteste, Matthew Paris und Humbert von Romans: B. M. Bolton, Some Thirteenth Century Women in the Low Countries, in: Nederlands Archief voor Kerkgeschiedenis 61 (1981) 7-29.

${ }^{34}$ E. Koch, De positie van vrouwen op de huwelijksmarkt in de middeleeuwen, in: Tijdschrift voor sociale geschiedenis 13 (1987) 150-172. Über die normalerweise erforderlichen materiellen Voraussetzungen für den Klostereintritt: $H$. Schuller, Dos-Praebenda-Peculium, 
derschaften mit ihrem geringeren religiös-moralischen Verbindlichkeitsgrad dafür nicht ausreichend genug erschien ${ }^{35}$. Frömmigkeits-, geistes- und bildungsgeschichtlich gesehen bedeutete dies, daß weiten Kreisen vor allem der Laienschaft eine größere Partizipation am liturgischen und religiösen Leben ermöglicht und ein leichterer Zugang zu den Glaubenswahrheiten verschafft wurde, als dies normalerweise angesichts der bestehenden "religiösen Vorbehalte und sozialen Widerstände" gegen die Laienbildung möglich war ${ }^{36}$. Dieser Effekt war bei dem in dieser Hinsicht besonders benachteiligten weiblichen Teil der Bevölkerung stark ausgeprägt. Frauen, denen aus persönlichen, sozialen bzw. demographischen Gründen die Eheschließung versagt oder der Zugang zu Klöstern, regulierten Stiften sowie anderen Institutionen des Ordenslebens versperrt war ${ }^{37}$, fanden in dem genannten Stand das, was sie sonst nur schwer oder gar nicht erreichen konnten:

in: Festschrift Friedrich Hausmann, hrsg. von H. Ebner (Graz 1977) 453-487; E. M. F. Koch, De Kloosterpoort als Sluitpost? (Maaslandse Monografiën 57, Limburg 1994). Über die Bedeutung der zuerst von K. Bücher gestellten „Frauenfrage im Mittelalter“" (Tübingen 21910) für die Entstehung des weiblichen Semireligiosentums zuletzt u.a.: P. Ketsch, Frauenarbeit im Mittelalter. Quellen und Materialien, hrsg. von A. Kubn (Düsseldorf 1983) I, 12-24 und W. Simons, Een zeker bestand: de zuid-nederlandse begijnen en de Frauenfrage, 13de - 18 de eeuw, in: Tijdschrift voor sociale geschiedenis 17 (1991) 126-146.

35 Einen Überblick über die weite Verbreitung des Bruderschaftswesens und die Erforschung seiner Geschichte verschaffen: $L$. Orioli, Per una rassegna bibliografica sulle confraternite medievali, in: Ricerche di Storia Sociale e Religiosa 17-18 (1980) 101-130; Le mouvement confraternel au Moyen Age. France, Italie, Suisse (Université de Lausanne, Publications de la Faculté des Lettres XXX. Collection de l'École française de Rome 97, Rom 1987); A. Czacharowski, Die Bruderschaften der mittelalterlichen Städte in der gegenwärtigen polnischen Forschung, in: Bürgerschaft und Kirche, hrsg. von J. Sydow (Stadt in der Geschichte 7, Sigmaringen 1980) 26-37; E. Rubin, Fraternities and Lay Piety in the Later Middle Ages, in: Einigungen und Bruderschaften in der spätmittelalterlichen Stadt, hrsg. von P. Johanek (Städteforschung A 32, Köln, Weimar, Wien 1993) 185-198; Cofradias, gremios y solidaridades en la Europa medieval. 19a Semana de Estudios medievales. Estella 24 de julio de 1992 (Pamplona 1993). T. Frank, Tendenze della recente ricerca tedesca sulle confraternite, in: Confraternite, Chiesa e Società. Aspetti e problemi dell'associazionismo laicale europeo in età moderna e contemporanea, hrsg. von $L$. Bertoldi Lenoci (Biblioteca della ricerca. Puglia storica 5, Bari 1995) 305-322.

36 K. Schreiner, Laienbildung als Herausforderung für Kirche und Gesellschaft. Religiöse Vorbehalte und soziale Widerstände gegen die Verbreitung von Wissen im späten Mittelalter und in der Reformation, in: Zeitschrift für Historische Forschung 11 (1984) 257-354; A. Löther, Grenzen und Möglichkeiten weiblichen Handelns im 13. Jahrhundert. Die Auseinandersetzung um die Nonnenseelsorge der Bettelorden, in: Rottenburger Jahrbuch für Kirchengeschichte 11 (1992) 223-240.

${ }^{37}$ K. Bosl, Armut, Arbeit, Emanzipation. Zu den Hintergründen der geistigen und literarischen Bewegung vom 11. bis zum 13. Jahrhundert, in: Beiträge zur Wirtschafts- und Sozialgeschichte des Mittelalters. Festschrift für Herbert Helbig zum 65. Geburtstag, hrsg. von K. Schulz (Köln 1976) 128-146; P. Dinzelbacher, Rollenverweigerung, religiöser Aufbruch und mystisches Erleben mittelalterlicher Frauen, in: Religiöse Frauenbewegung und mystische Frömmigkeit im Mittelalter, hrsg. von $P$. Dinzelbacher, D. R. Bauer (Beihefte zum Archiv für Kirchengeschichte 28, Köln, Wien 1988) 1-58; B. U. Weinmann, Mittelalterliche Frauenbewegungen. Ihre Beziehungen zur Orthodoxie und Häresie (Frauen in Geschichte und Gesellschaft, Pfaffenweiler 1990); vgl. auch Anm. 34. 
eine höhere Sensibilisierung für geistige und geistliche Werte, Erhöhung des Ansehens, Zugang zu der vorwiegend von Männern geprägten Welt der Kirche und des Glaubens und aktive Teilnahme an der Hebung des sozialen und kulturellen Niveaus sowohl in der Stadt als auf dem Lande, sowohl im privaten als auch im öffentlichen Bereich ${ }^{38}$. Mit der Möglichkeit zu größerer religiöser Sinnerfüllung und intensiverer "Selbstverwirklichung" ging die soziale Sicherung Hand in Hand. Das Leben als Inklusin oder die Zugehörigkeit zu Eremiten-, Bußbrüder-, Hospital-, Drittordens- und Beginengemeinschaften oder anderen Gruppierungen des devoten Lebens verbesserte ihre soziale Lage und verschaffte ihnen erhöhtes Ansehen, was besonders auf Frauen aus unteren Schichten und randständigen Bevölkerungsgruppen zutraf. Die individuelle Lebensführung als mulier devota, erst recht aber die Aufnahme in Institute des Semireligiosentums verhalfen ihnen nicht nur zu einer größeren sozialen Sicherheit, sie bewahrten sie auch vor gesellschaftlicher Marginalisierung oder gar Deklassierung ${ }^{39}$. In vielen Fällen boten sie sogar die Möglichkeit für Aufstieg und Prestigegewinn, so für viele der allein oder in kleinen Gruppen lebenden „Incarcerate“, Anachoretinnen oder Eremitinnen, die als Lehrerinnen, Ratgeberinnen und „mediatrici di grazie divine“ hohes Ansehen in ihrem jeweiligen sozialen Umfeld erlangten ${ }^{40}$.

Für Kirche und Gesellschaft hatte das Halbreligiosentum sowohl positive als auch negative Bedeutung. Welt- und Ordensklerus verfügten in den im Umkreis von Stift, Kloster und Konvent oder in selbständigen Gemeinschaften lebenden Semireligiosen über eine „Hilfstruppe“, die in Kloster und Welt Funktionen

38 E. Ennen, Frauen im Mittelalter (München ${ }^{21984) ; ~ d i e s ., ~ P o l i t i s c h e, ~ k u l t u r e l l e ~ u n d ~ k a r i t a-~}$ tive Wirksamkeit mittelalterlicher Frauen in Mission - Kloster - Stift - Konvent, in: Religiöse Frauenbewegung (wie Anm. 37), 59-82; B. Rath, Im Reich der Topoi. Nonnenleben im mittelalterlichen Österreich zwischen Norm und Praxis, in: L'Homme. Zeitschrift für feministische Geschichtswissenschaft 9 (1996) 122-134.

${ }^{39}$ F. Graus, Randgruppen der städtischen Gesellschaft im Spätmittelalter, in: Zeitschrift für Historische Forschung 8 (1981) 385-437; V. Bullough, The Prostitute in the Middle Ages, in: Studies in Medieval Culture 10 (Kalamazoo 1977) 9-12 (Literatur); Ch. Cohen, The Evolution of Women's Asylums. From Refuges for Ex-Prostitutes to Shelters for Battered Women (New York, Oxford 1992); P. Schuler, „Sünde und Vergebung“. Integrationshilfen für reumütige Prostituierte im Mittelalter, in: Zeitschrift für Historische Forschung 21 (1994) 145170; A. Simon, L'Ordre des Soeurs Pénitentes de Ste-Marie-Madeleine en Allemagne au XIII siècle (Freiburg 1918); Ph. Hofmeister, Die Exemption des Magdalenerinnenordens, in: Zeitschrift der Savigny-Stiftung für Rechtsgeschichte, Kan. Abt. 35 (1948) 305-329; F. Discry, La règle des Pénitentes de Ste-Marie-Madeleine, in: Académie Royale de Belgique. Bulletin de la Commission Royale d'histoire 121 (1956) 85-145.

${ }^{40}$ Neben der in den Anm. 25 und 31 genannten Literatur: A. Benvenuti Papi, Santità femminile nel territorio fiorentino e lucchese. Considerazioni intorno al caso di Verdiana da Castelfiorentino, in: Religiosità e società in Valdelsa nel basso medioevo. Atti del Convegno di S. Vivaldo, 29 settembre 1979 (Florenz 1980) 113f.; dies., Frati mendicanti e pinzochere in Toscana. Dalla marginalità sociale al modello di santità, in: La mistica femminile del Trecento. Atti del XXX Convegno storico internazionale del Centro di studi sulla spiritualità medievale, Todi 14-17 ottobre 1979 (Todi 1983) 107-137; A. B. Mulder-Bakker, Lame Margaret of Magdeburg. The Social Function of a Medieval Recluse, in: Journal of Medieval History 22 (1996) 155-169. 
wahrnahm, die sie selbst nicht ausüben wollten oder konnten. Dazu gehörten die materielle Absicherung und Unterstützung der Vollreligiosen, wie sie die Konversen mit und ohne Profess erbrachten ${ }^{41}$, die Erschließung bisher unerschlossener Regionen und die Sicherung von Straßen, Brücken und Schiffahrtswegen durch Eremiten und Eremitengruppen ${ }^{42}$, die Übernahme öffentlicher Funktionen und sozialer Dienstleistungen wie Seuchenbekämpfung, Krankenpflege, Begleitung von Sterbenden und Bestattung von Toten, die von Hospitalbrüdern, „Bizzoche“, Beginen und Begarden, aber auch anderen Devoten beiderlei Geschlechts erbracht wurden ${ }^{43}$, der Einsatz für kirchenpolitische Ziele wie die Beteiligung an Inquisition und Ketzerbekämpfung, aber auch die Rolle als Multiplikatoren im Dienste der Verkündigung und der Seelsorge, für die die schon bald unter den Einfluß der Bettelorden, speziell der Dominikaner, geratenen oberitalienischen Milizen als Beispiel angeführt werden können ${ }^{44}$. Eine weitere gesellschaftlich relevante Funktion des Semireligiosentums war die einer Vor- bzw. Durchgangsstufe für das Ordenswesen. Einzelnen Klöstern, Stiften und Konventen wurde aus den Kreisen der Semireligiosen geeigneter Nachwuchs zugeführt, bisher autonome semireligiose Gemeinschaften nahmen freiwillig oder auf Drängen der kirchlichen Obrigkeit den Status regulierter Korporationen an und wurden nicht selten zum Kern neuer Orden oder Kongregationen. Die Umwandlung „freier Gemeinschaften“ in ordines stand im 12. Jahrhundert am Anfang von Ritter-, Hospital- und Gefangenenbefreiungs- ${ }^{45}$, aber auch von Eremiten-, Mönchs- und Kanonikerorden ${ }^{46}$.

41 Vgl. Anm. 19.

$42 \mathrm{Vgl}$. Anm. 16 und 18.

43 Vgl. Anm. 26, 28 und 29.

44 G. G. Meersseman, Études sur les anciennes confrèries dominicaines I-IV, in: Archivum Fratrum Praedicatorum 20 (1950) 5-113, 21 (1951) 51-196, 22 (1952) 5-176, 23 (1953) 275-308, auch in: ders., G. P. Pacini, Ordo fraternitatis (wie Anm. 27), III, 1233-1289; N. J. Housley, Politics and Heresy in Italy. Anti-Heretical Crusades, Orders and Confraternities, in: Journal of Ecclesiastical History 33 (1982) 193-208; A. Thompson, Revival Preachers and Politics in Thirteenth-Century Italy. The Great Devotion (Oxford 1992).

45 Über die semireligiosen Anfänge der Ritter-, Hospital- und Gefangenenbefreiungsorden mit Quellen- und Literaturhinweisen: $K$. Elm, Die Spiritualität der geistlichen Ritterorden (wie Anm. 16). Danach in: Die Spiritualität der Ritterorden im Mittelalter, hrsg. von Z. Nowak (Ordines militares. Colloquia Torunensia Historica VII, Thorn 1993) 7-44; ders., Gli ordini militari. Un ceto de vita religiosa fra universalismo e particolarismo, in: Militia Sacra. Gli ordini militari tra Europa e Terra Santa, hrsg. von E. Coli, M. de Marco, F. Tommasi (Perugia 1994) 9-28.

46 Vgl. dazu u.a.: J. von Walter, Die ersten Wanderprediger Frankreichs. Studien zur Geschichte des Mönchtums I-II (Leipzig 1903-1906); E. Werner, Pauperes Christi. Studien zu sozial-religiösen Bewegungen im Zeitalter des Refompapsttums (Leipzig 1956); J. M. Bien$v e n u$, Préhistoire du francescanisme. Aspects préfranciscains de l'érémitisme et de la prédication itinérante dans la France de l'Ouest, in: Poverty in the Middle Ages, hrsg. von $D$. Flood (Werl 1975) 27-36; H. Leyser, Hermits and the New Monasticism. A Study of Religious Communities in Western Europe 1000-1150 (London 1984). G. Vittolo, Eremitismo, cenobitismo e religiosità laicale nel Mezzogiorno medievale, in: Benedictina 21 (1974) 79-129; M. Fuiano, Movimenti religiosi in Italia meridionale nella prima metà del secolo XII, in: Studi storici meridionali 1 (1981) 5-24; B. Vetere, Nuove forme di spiritualità e di vita monastica nell'Italia meridionale dei secoli XI-XII, in: S. Piero del Morone - Celestino V nel Medioevo 
Diese Tendenz setzte sich im 13. Jahrhundert fort, als der Häresie mit Recht oder Unrecht verdächtigte Gemeinschaften rekonziliert wurden, aus Bußbrüder- und Eremitengemeinschaften Orden wie diejenigen der Franziskaner, Karmeliten, Augustiner-Eremiten, Serviten, Sackbrüder, Pauliner und Kreuzherren hervorgingen $^{47}$, und verstärkte sich im Spätmittelalter bei der Regulierung allein oder in Gemeinschaft, in der Einsamkeit oder in der Stadt lebender Pönitenten bzw. Tertiaren ${ }^{48}$ sowie anderer semireligioser Vereinigungen, die zur Bildung selbständiger, nach anerkannter Regel lebender Verbände wie die der Alexianer und Celliten ${ }^{49}$

monastico. Atti del Convegno storico internazionale L'Aquila, 26-27 agosto 1988 (Convegni Celestiniani 3, L'Aquila 1989) 155-184.

47 K. Esser, Anfänge und ursprüngliche Zielsetzung des Ordens der Minderbrüder (Studia et documenta Franciscana IV, Leiden 1966); R. Manselli, San Francesco d'Assisi (Biblioteca di cultura 182, Rom 21980), Dtsch.: Franziskus. Der solidarische Bruder (Zürich, Einsiedeln, Köln 1984); Th. Debonnets, De l'intuition à l'institution. Les Franciscains (Paris 1983). E. Friedmann, The Latin Hermits of Mount Carmel. A Study in Carmelite Origins (Institutum Historicum Teresianum, Studia 1, Rom 1979); B. Z. Kedar, Gerard of Nazareth. A Neglected Twelfth-Century Writer in the Latin East. A Contribution to the Intellectual and Monastic History of the Crusader States, in: Dumbarton Oaks Papers 37 (1983) 55-77; E. Boaga, La storiografia carmelitana nei secoli XIII e XIV, in: The Land of Carmel. Essays in Honor of Joachim Smet, O.Carm, hrsg. von P. Chandler, K. J. Egan (Rom 1991) 125-154; A. Jotischky, The Perfection of Solitude. Hermits and Monks in the Crusader States (University Park PA 1995). A. de Meijer, R. Kuiters, Licet Ecclesiae Catholicae. Text, Commentary, in: Augustiniana 6 (1956) 9-36; K. Elm, Italienische Eremitengemeinschaften des 12. und 13. Jahrhunderts. Studien zur Vorgeschichte des Augustiner-Eremitenordens, in: L'Eremitismo in Occidente (wie Anm. 25), 491-559. F. dal Pino, I Servi di S. Maria dalle origini all'approvazione (1233 ca. - 1304) I-II (Université de Louvain. Recueil de travaux d'histoire et de philosophie IV, 49-50, Löwen 1972); L'ordine dei Servi di Maria nel primo secolo di vita. Atti del convegno storico Firenze, 23-24 maggio 1987 (Florenz 1988); I Sette santi nel primo centenario della canonizzazione (1888-1988). Convegno di studio Roma 3 - 8 ottobre 1988 (Rom 1990). R. M. Emery, The Friars of the Sack, in: Speculum 18 (1943) 323 f.; G. M. Giacomozzi, L'Ordine della Penitenza di Gesù Cristo. Contributo alla storia della spiritualità del sec. XIII (Scrinium historiale 2, Rom 1962); A. Amargier, Les frères de la penitence de Jesus-Christ ou du Sac, in: Provence historique 15 (1965) 158-167; K. Elm, Ausbreitung, Wirksamkeit und Ende der provençalischen Sackbrüder (Fratres de Poenitentia Jesu Christi) in Deutschland und den Niederlanden. Ein Beitrag zur kurialen und konziliaren Ordenspolitik des 13. Jahrhunderts, in: Francia 1 (1973) 257-324. E. Kisbán, A magyar Pálosrend törtenete I-II (Budapest 1938-1940); J. Horvath, Ursprung, Verbreitung und Tätigkeit der Pauliner in der Diözese Fünfkirchen von 1225 bis 1526 (Diss. theol., Wien 1938); G. Sarbak, Entstehung und Frühgeschichte des Ordens der Pauliner, in: Zeitschrift für Kirchengeschichte 99 (1988) 93-103. Uber die verschiedenen Kreuzherrenorden mit Quellen- und Literaturangaben: K. Elm, Kreuzherren, in: Lexikon des Mittelalters V (1991) 1500-1502.

48 . Pazzelli, Il Terz' Ordine Regolare di San Francesco attraverso i secoli. Rielaborazione critica e sviluppo dell'opera storica del Raniero Luconi T.O.R. (Rom 1958); G. Andreozzi, Il Terzo Ordine Regolare di San Francesco nella sua storia e nelle sue legge I-III (Rom 1993-95). Vgl. auch Anm. 28.

49 C. Greifenhagen, Die Alexianer und Alexianerinnen Deutschlands. Eine kirchengeschichtliche Studie, in: Hannoverland 4 (1910) 9-14, 28-35, 55-68; A. Huyskens, Die Anfänge der Aachener Alexianer im Zusammenhang der Ordens- und Ortsgeschichte, in: Zeitschrift des Aachener Geschichtsvereins 48/49 (1928) 190-256; J. Arsen, Die Begarden und die Sackbrüder in Köln, in: Annalen des Historischen Vereins vom Niederrhein 115 (1929) 167179; J. Wiegers, Die Aachener Alexianerbrüder. Ihre Geschichte und ihr Ordensgeist 
oder gar autonomer Orden wie die der Franziskanerobservanten und Kapuziner ${ }^{50}$, Hieronymiten, Ambrosianer und Jesuaten ${ }^{51}$ führte. Im individuellen Bereich lassen sich solche Übergänge bei Ordensstiftern und Kongregationsgründern beobachten, die den status medius als eine Art Durchgangsstation betrachteten, in der es möglich war, als Angehörige eines durch Tradition und Recht legitimierten Standes, also ohne Diskreditierung, neue Formen des religiösen Lebens zu suchen und zu erproben. Norbert von Xanten führte die vita eremitica, bevor er zur Wanderpredigt nach Frankreich aufbrach, Stifter des Prämonstratenserordens und schließlich Erzbischof von Magdeburg wurde ${ }^{52}$. Franz von Assisi erwog mit seinen ersten Gefährten, utrum inter homines conversari deberent, an ad loca solitaria se conferre, und brach als "laico-penitente-eremita irregolare ed independente" nach Rom auf, wo er von Innozenz III. die Ermutigung zur Gründung eines Ordens erhielt ${ }^{53}$. Der Weg, den Norbert und Franziskus nach ihrer Abwen-

(Aachen 1956); J. C. Kaufmann, Tamers of Death I: The History of the Alexian Brothers from 1300 to 1789 (New York 1976), dtsch.: Die Geschichte der Alexianerbrüder I-II (Aachen 1976-78); H. Heitzenröder, Geschichte der Begarden (Alexianer) in Frankfurt am Main, in: Archiv für mittelrheinische Kirchengeschichte 31 (1979) 55-74; B. Hotz, Beginen und Willige Arme im spätmittelalterlichen Hildesheim (Schriftenreihe des Stadtarchivs und der Stadtbibliothek Hildesheim 17, Hildesheim 1988); 500 Jahre Alexianerbrüder in Neuss 1490 1990 (Neuss 1990). Ein „Monasticon“ der nordwesteuropäischen, später zu Alexianern bzw. Celliten gewordenen Begarden hat M. Birken 1972 in seiner ungedruckten Freiburger Staatsexamensarbeit über „Die Niederlassungen der Alexianer in Nordwesteuropa“ vorgelegt.

50 M. Sensi, Le Osservanze francescane nell'Italia centrale. Secoli XIV-XV (Bibliotheca Seraphico-Capuccina 30, Rom 1985); D. Nimmo, Reform and Division in the Medieval Franciscan Order from Saint Francis to the Foundation of the Capuchins (Ebd. 33, Rom 1987); Merlo, Eremitismo nel francescanesimo (wie Anm. 16), 29-50; M. Sensi, Dal movimento eremitico alla regolare osservanza francescana. L'opera de Fra Paolucci Trinci (Assisi 1992).

51 I. de Siguënza, Historia de la Orden de San Jeronimo I-II, hrsg. von J. Catalina Garcia (Madrid 1907-1909); J. Revuelta Somato, Los jerónimos I: La fundación 1373-1414 (Guadalagara 1982); C. Dos Santos, Os Jerónimos em Portugal dos origines aos fins do século XVIII (Porto 1980); J. R. L. Highfield, The Jeronimites in Spain, their Patrons and Success 13731516, in: Journal of Ecclesiastical History 34 (1983) 513-533; G. Turazza, S. Ambrogio ad Nemus in Milano. Chiesa e monastero. Notize storiche dall'anno 357 al 1912 (Mailand 1914); C. Gennaro, Giovanni Colombini e la sua brigata, in: Bullettino dell'Istituto storico per il medio evo 81 (1969) 237-271; G. Dufner, Geschichte der Jesuaten (Nomine e dottrine 21, Rom 1975); A. Benvenuti Papi, Le donne di Giovanni Colombini, in: dies., „In castro poenitentiae" (wie Anm. 31), 415-528.

52 W. M. Grauwen, Norbert, Erzbischof von Magdeburg (1126-1134). Zweite überarbeitete Auflage, übersetzt und bearbeitet von L. Horstkötter (Duisburg 1986); F. J. Felten, Norbert von Xanten. Vom Wanderprediger zum Kirchenfürst, in: Norbert von Xanten. Adeliger Ordensstifter - Kirchenfürst, hrsg. von K. Elm (Köln 1984) 69-157; S. Weinfurter, Norbert von Xanten und die Entstehung des Prämonstratenserordens, in: Barbarossa und die Prämonstratenser (Schriften zur staufischen Geschichte und Kunst 10, Göppingen 1989) 67$100 ; K$. Elm, Norbert von Xanten, in: Rheinische Lebensbilder 15, hrsg. von $F . J$. Heyen (Köln 1995) 7-21.

53 Thomas von Celano, Vita prima s. Francisci, in: Legendae sancti Francisci Assisiensis saeculi XIII et XIV conscriptae (Analecta Franciscana X, Quarracchi - Florenz 1926/41) 28; L. Pellegrini, L'esperienza eremitica di Francesco e dei primi francescani, in: Francesco d'As- 
dung von der Welt einschlugen, war keineswegs außergewöhnlich. Ihn gingen vor und nach ihnen zahlreiche vergessene oder aber zur Ehre der Altäre gelangte Männer und Frauen, die wie sie zu neuen Zielen aufbrachen, ihren bisherigen Status aufgaben, Reformen durchsetzen wollten oder nichts anderes anstrebten als eine Änderung der bestehenden Verhältnisse - ohne dabei Gefahr zu laufen, als Outsider oder gar Häretiker in Mißkredit zu geraten ${ }^{54}$.

Die geistliche und weltliche Obrigkeit hatte bei aller Wertschätzung der Leistungen der Semireligiosen ihre Vorbehalte gegen deren Lebensweise. Hierarchie und Orden sahen in ihr eine Gefährdung ihrer Monopolstellung, beklagten Ungehorsam und Disziplinlosigkeit und fühlten sich durch anmaßendes Auftreten, unautorisierte Beschäftigung mit der Heiligen Schrift sowie tatsächliche oder vermeintliche okkulte Praktiken und von der Orthodoxie abweichende Auffassungen provoziert, während die weltliche Obrigkeit den semireligios lebenden Personen und nichtregulierten Gemeinschaften nur so lange positiv gegenüberstand, wie sie sich loyal verhielten, ja sich als soziale Ordnungsfaktoren erwiesen. Die Unterstützung durch die weltliche Obrigkeit nahm jedoch in dem Maße ab, in dem sie sich der Integration in das öffentliche Leben widersetzten, als Mitglieder des geistlichen Standes verstanden und dessen Sonderrechte für sich beanspruchten, die Eidesleistung ablehnten, Steuerzahlung und Kriegsdienst verweigerten, Wirtschafts- und Gewerbemonopole durchbrachen oder gar zu einer politischen Opposition wurden ${ }^{55}$, ganz zu schweigen von der öffentlichen Meinung, die bei aller Wertschätzung der Frömmigkeit und des „sozialen Engagements“ der laici religiosi keineswegs mit Kritik an dem sparte, was sie als Bigotterie oder Laxheit der in der "Welt" lebenden, aber dennoch ihr nicht ganz angehörenden devoten Männer und Frauen ansah ${ }^{56}$.

sisi e francescanesimo dal 1216 al 1226. Atti del IV Convegno Internazionale Assisi, 15-17 ottobre 1976 (Assisi 1977) 279-313.

${ }^{54}$ Siehe für das 12. Jahrhundert neben der in Anm. 46 genannten Literatur: J. Bequet, L'érémitisme clérical et laïc dans l'ouest de la France, in: L'Eremitismo in Occidente (wie Anm. 25), 182-204; G. G. Meersseman, Eremitismo e predicatione itinerante dei secoli XI e XII, in: ebd. 164-179; L. Milis, Ermites et chanoines réguliers au XIIe siècle, in: Cahiers de civilisation médiévale 22 (1979) 39-80; L. Donnat, La spiritualité du désert au XIIe siècle, in: Collectanea Cisterciensia 53 (1991) 146-156. Zur statistischen Erfassung von zu Ordensfrauen gewordenen „Religiosen jenseits des monastischen Raums“: B. Wilms, „Amatrices Ecclesiarum “. Untersuchung zur Rolle und Funktion der Frauen in der Kirchenreform des 12. Jahrhunderts (Bochumer Historische Studien. Mittelalterliche Geschichte 5, Bochum 1987) 361-369.

55 Vgl. zum Folgenden die in Anm. 16 genannte Literatur.

$56 \mathrm{~J}$. Leclercq, Le poème de Payen contre les faux ermites, in: Revue bénédictine 68 (1958) 52-86; J. Howe, The Awesome Hermit. The Symbolic Significance of the Hermit as a Possible Research Perspective, in: Numen 30 (1983) 106-119; J. Batany, Les convers chez quelques moralistes des XII ${ }^{e}$ et XIII' siècles, in: Cîteaux 20 (1969) 241-259; J. van Engen, Late Medieval Anticlericalism. The Case of New Devout, in: Anticlericalism in Late Medieval and Early Modern Europe, hrsg. von P. A. Dykema, H. A. Oberman (Studies in Medieval and Reformation Thought 51, Leiden, New York, Köln 1993) 19-52; C. Märtel, Pos verstockt weyber? Der Streit um die Lebensform der Regensburger Damenstifte im ausgehenden 15. Jahrhundert, in: Regensburg, Bayern und Europa. Festschrift für Kurt Reindel zum 70. Geburts- 
IV.

Die Unterschiede zwischen den individuell praktizierten Formen des asketischen Lebens der christlichen Antike und des frühen Mittelalters, den Hospital-, Eremiten-, Büßer- und Tertiarengemeinschaften des 12. und 13. Jahrhunderts, den spätmittelalterlichen Beginen und Begarden oder den Brüdern und Schwestern vom Gemeinsamen Leben, machen es schwer, über viele Jahrhunderte und weite Räume hinweg das sie Einigende zu erkennen, trotz der Vielfalt der sich nicht selten überschneidenden Erscheinungsformen, wechselnden Bezeichnungen und voneinander abweichenden Selbst- und Fremddefinitionen die Einheit eines Standes zu erkennen und diesen von den nicht minder schwer definierbaren Bruderschaften und „brüderlichen“ Vereinigungen sowie den zahlreichen, dem Semireligiosentum nach Genese, äußerer Erscheinungsform und Lebensweise verwandten "häretischen" Ausprägungen des mittelalterlichen Genossenschaftswesens abzugrenzen ${ }^{57}$. Dennoch lassen sich gewisse Übereinstimmungen zwischen virgines et viduae, canonici et canonissae, confratres et confratrissae, inclusi et eremitae, poenitentes et disciplinati, fratres communis vitae et mulieres devotae feststellen. Was sie ungeachtet aller örtlich und zeitlich bedingter Unterschiede in Lebensführung und Lebensstil miteinander verband, war der Charakter des Intermediären, Ambivalenten und Transitorischen. Ihr Stand verpflichtete sie zu häufigerem Sakramentenempfang, einem intensiveren Gebetsleben und größeren asketischen Leistungen als die Laien, ohne von ihnen die Gesamtheit der mit dem status religiosus verbundenen Pflichten zu fordern. Er erlegte ihnen bestimmte soziale Bindungen auf, hinderte sie jedoch nicht an der Rückkehr in die Welt, verlieh ihnen bestimmte Privilegien des Ordensstandes, entließ sie jedoch nicht aus ihren bisherigen Rechtsverhältnissen und der Abhängigkeit vom lokalen Klerus, forderte den Verzicht auf die "modische“ Kleidung der Laien, versagte ihnen aber den habitus religiosus, veranlaßte sie zur Vertiefung ihres Glaubens, verweigerte ihnen jedoch eine theologische Schulung, öffnete ihnen das Buch, lehrte sie allerdings nicht das Latein, forderte das häufige Gebet, verweigerte ihnen jedoch die volle Teilnahme an Liturgie und Divinum officium: Er schickte damit seine Angehörigen in den Raum zwischen Religiosen und Laien. In dieser ambivalenten Situation, die man mit Formulierungen wie vita regularis sine regula, via media, status tertius, status

tag, hrsg. von L. Kolmer, P. Segl (Regensburg 1995) 365-401; U. Andermann, Die unsittlichen und disziplinlosen Kanonissen. Ein Topos und seine Hintergründe, aufgezeichnet an Beispielen sächsischer Frauenstifte (11.-13. Jh.), in: Westfälische Zeitschrift 146 (1996) 39-63.

57 Zum Problem der Terminologie und Definition neben der in Anm. 35 genannten Lit.: P. Michaud-Quantin, Universitas. Expression du mouvement communitaire dans le MoyenAge (Paris 1970); F. Remling, Bruderschaften als Forschungsgegenstand, in: Jahrbuch für Volkskunde 3 (1980) 81-112; R. Schmidt-Wiegand, Hanse und Gilde. Genossenschaftliche Organisationsformen im Bereich der Hanse und ihre Bezeichnungen, in: Hansische Geschichtsblätter 100 (1982) 21-40; F. Irsigler, Zur Problematik der Gilde- und Zunftterminologie, in: Gilden und Zünfte. Kaufmännische Genossenschaften im frühen Mittelalter. Ein Beitrag zum Problem der sozialgeschichtlichen Kontinuität zwischen Antike und Mittelalter, hrsg. von B. Schwineköper (Vorträge und Forschungen 29, Sigmaringen 1985) 53-70. 
medius zu beschreiben versuchte, entstand bei aller Verschiedenheit, die nicht zu übersehen ist, eine eigene Spiritualität, ja Kultur, der sich die Forschung erst seit einigen Jahrzehnten zuwendet. Was sie ähnlich wie die übrigen Formen genossenschaftlich ausgerichteter geistlicher Gemeinschaftsbildung sowohl orthodoxen als heterodoxen Charakters kennzeichnet, ist in erster Linie die auf der Voraussetzung weitgehender „brüderlicher" Gleichheit beruhende Organisationsstruktur, die konventikelartige Versammlung, das paraliturgische Gebet und das geistliche Lied, die Predigt und die gegenseitige Ermahnung, die Lektüre und Verbreitung volkssprachlichen Schrifttums und schließlich das Streben nach individueller, nicht selten den Rahmen des Üblichen, ja der Orthodoxie sprengender religiöser Erkenntnis und Erfahrung.

Die hier in groben Zügen vorgenommene Skizzierung des Phänomens „Semireligiosentum" läßt sich präzisieren, wenn man versucht, die Rechtsstellung des status religiosus largo modo, als welchen Heinrich von Segusia, der Hostiensis, im 13. Jahrhundert diesen "Stand" bezeichnet, genauer zu definieren ${ }^{58}$. Abgesehen von den z.T. bis in die Frühzeit der Kirche zurückgehenden Bestimmungen für "gottgeweihte "Jungfrauen und Witwen ${ }^{59}$, Eremiten ${ }^{60}$, Hospitalbrüder 61 und Pönitenten $^{62}$, Zusammenschlüsse von Laien und Klerikern ${ }^{63}$ sowie das Konversen-

58 Summa aurea (Venedig 1574, ND Turin 1963) 1108. Mit einer abweichenden Interpretation des Terminus: P. Biller, Words and the Medieval Notion of „Religion“, in: Journal of Ecclesiastical History 36 (1985) 351-366.

${ }^{59} \mathrm{H}$. Koch, Virgines Christi. Das Gelübde der gottgeweihten Jungfrauen in den ersten Jahrhunderten (Texte und Untersuchungen zur Geschichte der altchristlichen Literatur 31, Leipzig 1907); F. de Vizmanos, Las Vírgenes cristianas de la Iglesia primitiva (Madrid 1949); $R$. Metz, La consecration des vierges dans l'église romaine. Étude d'histoire et de la liturgie (Bibliothèque de l'Institut du Droit Canonique de l'Université de Strasbourg, Straßburg 1954); L. Bopp, Das Witwentum als organische Gliedschaft im Gemeinschaftsleben der alten Kirche (Mannheim 1965); J. Bugge, Virginitas. An Essay in the History of a Medieval Ideal (Archives internationales d'histoire des idées. Séries mineur 17, Den Haag 1975). Über die frühchristlichen Diakonissen u.a.: J. G. Davies, Deacons, Deaconesses and the Minor Orders in the Patristic Period, in: Journal of Ecclesiastical History 14 (1963) 1-15.

60 Neben der in Anm. 18 genannten Literatur: C. Lialine, P. Doyère, Erémitisme, in: Dictionnaire de la spiritualité IV (1960) 936-982; Th. Spidlik, J. Sainsaulieu, Ermites, in: Dictionnaire d'histoire et de géographie ecclésiastique XV (1963) 766-787.

${ }^{61}$ Neben der in Anm. 26 genannten Literatur: S. Reicke, Das deutsche Spital und sein Recht im Mittelalter II. Das deutsche Spitalrecht (Kirchenrechtliche Abhandlungen 111-114, Stuttgart 1932); J. Imbart, Les hôpitaux en droit canonique (Paris 1947); E. Nasalli-Rocca, Il diritto ospitaliero nei suoi fondamenti storici (Mailand 1956); J. Sydow, Spital und Stadt in Kanonistik und Verfassungsgeschichte des 14. Jahrhunderts, in: Der deutsche Territorialstaat im 14. Jahrhundert (Vorträge und Forschungen 13, Sigmaringen 1970) I, 175-195.

${ }^{62}$ Neben der in Anm. 27 angeführten Literatur: B. Poschmann, Die abendländische Kirchenbuße am Ausgang des christlichen Mittelalters (Münchener Studien zur historischen Theologie 7, München 1928); ders., Die abendländische Kirchenbuße im frühen Mittelalter (Breslauer Studien zur historischen Theologie 16, Breslau 1930); J. A. Jungmann, Die lateinischen Bußriten in ihrer geschichtlichen Entwicklung (Forschungen zur Geschichte des innerkirchlichen Lebens 3-4, Innsbruck 1932); F. Kerf, Libri poenitentiales und kirchliche Strafgerichtsbarkeit bis zum Decretum Gratiani, in: Zeitschrift der Savigny-Stiftung für Rechtsgeschichte. Kan. Abt. 75 (1989) 23-57; K.-J. Klär, Das kirchliche Bußinstitut von den Anfängen 
tum $^{64}$ und andere mit Kloster und Stift verbundene semireligiose Institute, kennen das vorgratianische Kirchen- und das ältere Ordensrecht keine ausdrückliche und umfassende Definition dessen, was man heute als Semireligiosentum bezeichnet. Das dürfte seinen Grund in erster Linie darin haben, daß Päpste und Bischöfe, Konzilien und Synoden vor den im 12. Jahrhundert einsetzenden Bemühungen um die Kodifizierung des Kirchenrechts und der damit verbundenen Präzisierung der Rechtsstellung des Welt- und Ordensklerus sowie der Laien noch keinen Anlaß zu einer rechtlichen Definition des sich zwischen diesen Ständen etablierenden geistlichen Lebens sahen, ja sich seiner als einer eigenen forma vitae noch gar nicht bewußt waren bzw. bewußt sein konnten ${ }^{65}$. Erst im Laufe des 12., vor allem aber

bis zum Konzil von Trient (Europäische Hochschulschriften, Reihe XXIII, Bd. 413, Frankfurt 1991); C. Carpaneta, Lo stato dei penitenti nel 'Corpus Juris Canonici', in: I Frati Penitenti di San Francesco (wie Anm. 28), 9-19.

63 G. M. Monti, Le confraternite medievali dell'Alta e Media Italia I-II (Venedig 1927); J. $D u b r$, La confrérie dans la vie de l'Eglise, in: Revue d'histoire ecclésiastique 25 (1939) $437-$ 478; G. Le Bras, Les confréries chrétiennes. Aperçus historiques, problèmes et propositions, in: Revue historique de droit français et étranger 19-20 (1940-41) 310-363; J. Sydow, Fragen zu Gilde, Bruderschaft und Zunft im Lichte von Kirchenrecht und Kanonistik, in: Gilden und Zünfte. Kaufmännische und gewerbliche Genossenschaften im frühen und hohen Mittelalter, hrsg. von B. Schwineköper (Vorträge und Forschungen 29, Sigmaringen 1985) 113126; W. Astrabt, Die Vita communis der Weltpriester (Kanonische Studien und Texte 22, Amsterdam 1967); M. Zacherl, Die Vita communis als Lebensform des Klerus in der Zeit zwischen Augustinus und Karl dem Großen, in: Zeitschrift für katholische Theologie 97 (1970) 385-425; P. Moraw, Über Typologie, Chronologie und Geographie der Stiftskirche im deutschen Mittelalter, in: Untersuchungen zu Kloster und Stift (Veröffentlichungen des MaxPlanck-Instituts für Geschichte 68. Studien zur Germania Sacra 14, Göttingen 1980) 9-37; C. Cracco, La fondazione dei canonici secolari di S. Giorgio in Alga, in: Rivista di storia della Chiesa in Italia 13 (1959) 70-81; I. Crusius, Gabriel Biel und die oberdeutschen Stifte der Devotio moderna, in: Studien zum weltlichen Kollegiatsstift in Deutschland, hrsg. von I. Crusius (Veröffentlichungen des Max-Planck-Instituts für Geschichte 114. Studien zur Germania Sacra 18, Göttingen 1995) 298-322; G. G. Meersseman, Die Klerikervereine von Karl dem Großen bis Innozenz III., in: Zeitschrift für Schweizer Kirchengeschichte 46 (1952) 1-42, 81-112; H. Klein, Die Entstehung und Verbreitung der Kalandsbruderschaften in Deutschland (Diss. Saarbrücken 1958/1963); Th. Helmert, Kalendae, Kalenden, Kalende, in: Archiv für Diplomatik 26 (1980) 1-55; M. Prietzel, Die Kalande im südlichen Niedersachsen. Zur Entstehung und Entwicklung von Priesterbruderschaften im Spätmittelalter (Veröffentlichungen des Max-Planck-Instituts für Geschichte 117, Göttingen 1995).

64 Neben der in Anm. 19 genannten Lit.: Ph. Hofmeister, Die Rechtsverhältnisse der Konversen, in: Österreichisches Archiv für Kirchenrecht 19 (1962) 3-47.

65 R. J. Cox, A Study of the Juridic Status of Laymen in the Writings of Medieval Canonists (Washington D.C. 1959); L. Prosdocimi, Clerici e laici nella società occidentale, in: Proceedings of the Second International Congress of Medieval Canon Law, hrsg. von St. Kuttner, J. J. Ryan (Monumenta Juris Canonici C: Subsidia 1, Città del Vaticano 1965) 105-122; ders., Lo stato di vita laicale nel diritto canonico dei secoli XI e XII, in: I laici nella „Societas christiana“ (wie Anm. 13), 55-77; L. Hertling, Die „Professio“ der Kleriker und die Entstehung der drei Gelübde, in: Zeitschrift für katholische Theologie 56 (1932) 148-174; C. Bock, La promesse d'obéissance ou la „professio regularis“ (Westmalle 1955); C. Capelle, Le voeu d'obéissance dès origines au XII siècle. Étude juridique (Bibliothèque du droit canonique et du droit romain 2, Paris 1958); J. Laudage, Priesterbild und Reformpapsttum im 11. Jahrhun- 
des 13. Jahrhunderts ist es im Rückgriff auf die bereits früher für bestimmte Formen der vita media getroffenen Bestimmungen zu einer Definition des Semireligiosentums gekommen. Das geschah jedoch nicht auf einen Schlag, sondern Schritt für Schritt und bei unterschiedlichen Gelegenheiten als Reaktion auf sich im Laufe der Zeit ergebende Notwendigkeiten, was bedeutet, daß es sich bei den auf solche Weise zustandegekommenen Festlegungen des Semireligiosentums um Abgrenzungen einmal von Welt- und Ordensklerus und zum anderen von der vita dissoluta der Laien, speziell jener, die sich der Häresie verdächtig machten oder mit Recht als Ketzer angesehen wurden, handelte. Päpste, Konzilien und Episkopat sahen sich seit dem 12. Jahrhundert, verstärkt im 13. Jahrhundert gezwungen, bei der Abgrenzung der vielfältigen Formen des Semireligiosentums von den Laien und den gleichzeitig in großer Zahl und verschiedener Form auftretenden Häresien auf der einen und der nicht minder geringen Zahl neuer Orden auf der anderen Seite zu einer Umschreibung des legitimen Wirkungsraumes dieses Zwischenstatus zu kommen. Diese Abgrenzung wurde schon bei der „Regulierung" der Hospital- und Ritterorden des 12. Jahrhunderts erforderlich, wie Entstehung, Organisation und Selbstverständnis ihrer bedeutendsten Vertreter, der Johanniter und Templer, erkennen läßt ${ }^{66}$. Sie war die Voraussetzung für die von Innozenz III. betriebene Rekonzilierung häresieverdächtiger Gemeinschaf-

dert (Beihefte zum Archiv für Kulturgeschichte 22, Köln, Wien 1984). Vgl. dazu: H. Jacobs, Kirchenfreiheit und Priesterbild, in: Historisches Jahrbuch 10 (1988) 448-462.

${ }^{66}$ G. Schnürer, Die ursprüngliche Templerregel (Studien und Darstellungen auf dem Gebiet der Geschichte III, 1-2, Freiburg 1903). Als die jüngsten Publikationen zur Entstehung und Organisation des Templerordens seien genannt: $F$. Tommasi, „Pauperes commilitones Christi“". Aspetti e problemi delle origini Gerosolimitane, in: ,Militia Christi' e crociata (wie Anm. 16), 443-476; P. Vial, La papauté, l'exemption et l'ordre du Temple, in: Papauté, monachisme et théories politiques I. Le pouvoir et l'institution ecclésiale. Etudes d'histoire médiévale offertes à Marcel Pacaut (Collection d'histoire et d'archéologie médiévale 1, Lyon 1994) 173180; $M$. Barber, The New Knighthood. A History of the Order of the Temple (Cambridge 1994); A. Luttrell, The Earliest Templars, in: Autour de la première croisade, hrsg. von $M$. Bastard (Byzantina Sorbonensia 14, Paris 1996) 193-202; F. Tommasi, Per i rapporti tra Templari e Cisterciensi. Orientamenti e indirizzi di ricerca, in: I Templari. Una vita tra riti cavallereschi e fedeltà alla Chiesa. Atti del I Convegno "I Templari e San Bernardo di Chiaravalle“ Certosa di Firenze 23-24 ottobre 1992 (Florenz 1995) 227-274; J. Leclercq, Un document sur les débuts des Templiers, in: Revue d'histoire ecclésiastique 52 (1957) 81-91, auch in: ders., Recueil des études sur saint Bernard et ses écrits (Rom 1966) II, 87-99; Ch. Schaffert, Lettre inédite de Hugues de Saint-Victor aux chevaliers du Temple, in: Revue d'ascétique et de mystique 34 (1958) 275-299; R. Hiestand, Die Anfänge der Johanniter, in: Die geistlichen Ritterorden Europas, hrsg. von J. Fleckenstein, M. Hellmann (Vorträge und Forschungen 26, Sigmaringen 1980) 31-80; G. T. Lagleder, Die Ordensregeln der Johanniter/Malteser. Die geistlichen Grundlagen des Johanniter-Malteserordens samt einer Edition und Übersetzung der drei ältesten Regelhandschriften (St. Ottilien 1983); M. Matzke, De origine Hospitaliorum Hiersolymitanum. Vom klösterlichen Pilgerhospital zur internationalen Organisation, in: Journal of Medieval History 22 (1996) 1-23. A. Luttrell, The Earliest Hospitallers, in: Montjoie. Studies in Honour of Hans Eberhard Mayer, hrsg. von B. Z. Kedar, J. Riley-Smith, R. Hiestand (Aldershot 1997) 37-54. Vgl. auch: Elm, Die Spiritualität der geistlichen Ritterorden (wie Anm. 6), 477-518. 
ten wie derjenigen der Armen Katholiken und Humiliaten ${ }^{67}$, aber auch der Verurteilung der sich nicht zu Kompromissen bereitfindenden Waldenser ${ }^{68}$. Sie erfolgte in den Stellungnahmen zu der in der Mitte des 13. Jahrhunderts ihren Höhepunkt erreichenden Bußbewegung ${ }^{69}$, in den im 14. Jahrhundert auf eine für die Betroffenen bedrohlich zwischen Verurteilung und Anerkennung schwankenden offiziellen Verlautbarungen über die Beginen und Begarden vor allem am Oberrhein ${ }^{70}$.

67 A. Luchaire, Innocent III, le concil de Lateran et la réforme de l'église (Paris 1908); A. Fliche, Innocent III et la réforme de l'église, in: Revue d'histoire ecclésiastique 44 (1949) 90-152; M. Maccarone, Riforme e innovazioni di Innocenzo III nella vita religiosa, in: ders., Studi su Innocenzo III (Italia Sacra 17, Padua 1972) 223-337; J. B. Pierron, Die katholischen Armen (Freiburg 1911); K.-V. Selge, L'aile droite du mouvement Vaudois et la naissance des Pauvres Catholiques et des Pauvres Réconciliés, in: Vaudois Languedociens et Pauvres Catholiques (Cahiers de Fanjeaux 2, Toulouse 1967) 227-243; B. Bolton, Innocent III's Treatment of the Humiliati, in: Popular Beliefs and Practice, hrsg. von C. J. Cuming, D. Baker (Studies in Church History 8, Cambridge 1972) 73-82; dies., Sources for the Early History of the Humiliati, in: The Material, Sources and Methods of Ecclesiastical History, hrsg. von D. Baker, in: ebd. 11 (New York 1975) 125-133; P. Alberzoni, Gli inizi degli Umiliati: una reconsiderazione, in: La conversione alla povertà (wie Anm. 17), 187-237; Forschungs- und Literaturüberblick: $K$.-V. Selge, Humiliaten, in: Theologische Realenzyklopädie XV (Berlin, New York 1986) 691-696; L. Paoloni, Le Umiliate a lavoro. Appunti fra storiografia e storia, in: Bulletino storico italiano per il medio evo 97 (1991) 229-265.

68 K.-V. Selge, Die ersten Waldenser. Mit Edition des Liber antiheresis des Durandus von Osca (Arbeiten zur Kirchengeschichte 37 I/II, Berlin 1967); M. Schneider, Europäisches Waldensertum im 13. und 14. Jahrhundert. Gemeinschaftsformen - Frömmigkeit - Sozialer Hintergrund (ebd. 51, Berlin, New York 1981).

69 Neben dem grundlegenden Dossier de l'Ordre de la Pénitence au XIIIe siècle (Spicilegium Friburgense 7, Freiburg, Schweiz, 1961) von G. G. Meersemann vgl. u.a.: G. Odoardi, L'Ordine della Penitenza nei documenti papali del secolo XIII, in: I Frati Penitenti di San Francesco nella società (wie Anm. 28), 21-49 und die in den Anm. 27 und 62 genannte Literatur.

$70 \mathrm{~J}$. C. Schmitt, Mort d'une hérésie. L'Église et les clercs face aux béguines et aux béghards du Rhin supérieur du XIVe au XVe siècle (Civilisations et Sociétés 56, Paris 1978); D. Phillips, Beguines in Medieval Strasbourg. A Study on the Social Aspect of Beguine Life (Stanford 1941); A. Patschovsky, Straßburger Beginenverfolgungen im 14. Jahrhundert, in: Deutsches Archiv zur Erforschung des Mittelalters 30 (1974) 56-198; M. Straganz, Zum Beghardenund Beginenstreit in Basel zu Beginn des 15. Jahrhunderts, in: Alemannia 27 (1900) 20-28; $B$. Degler-Spengler, Die Beginen in Basel, in: Basler Zeitschrift für Geschichte und Altertumskunde 69 (1969) 5-83; B. Neidiger, Mendikanten zwischen Ordensideal und städtischer Realität. Untersuchungen zum wirtschaftlichen Verhalten der Bettelorden in Basel (Berliner Historische Studien 5, Ordensstudien III, Berlin 1981); B. Degler-Spengler, Der Beginenstreit in Basel, 1400-1411. Neue Forschungsergebnisse und weitere Fragen, in: Il movimento francescano della penitenza nella società medioevale (wie Anm. 28), 95-105; A. Patschovsky, Beginen, Begarden und Terziaren im 14. und 15. Jahrhundert. Das Beispiel des Basler Beginenstreits (1400/4-1411), in: Festschrift für Eduard Hlawitschka zum 65. Geburtstag, hrsg. von K. R. Schnith, R. Pauler (Münchener Historische Studien, Abt. Mittelalterliche Geschichte 5, Kallmünz 1993) 403-418; H.-J. Schiewer, Auditionen und Visionen einer Begine. Die selige Schererin<, Johannes Mulberg und der Basler Beginenstreit. Mit einem Textabdruck, in: Die Vermittlung geistlicher Inhalte im deutschen Mittelalter, hrsg. von T. R. Jackson, N. F. Palmer, A. Suerbaum (Tübingen 1996) 289-317. Mit Hinweisen auf die noch wenig untersuchte Behandlung der Beginen und Begarden in Nordwesteuropa: I. Wormgoor, De 
Sie fand ihren Niederschlag in Dekreten, Synodalbeschlüssen, Regeln, Statuten, Proposita, Hausordnungen, Memorialia und Defensoria, die bei der Umschreibung des als legitim geltenden Lebens- und Wirkungsraumes von Eremiten, Bußbrüdern, Beginen, Begarden und anderer semireligios lebender Personen und Gruppen eine auffällige Übereinstimmung an den Tag legen ${ }^{71}$. Sie verlangen unisono eine honesta vita, eine Haltung der humilitas, der recta intentio, der devotio, der simplicitas und reverentia, fordern den Verzicht auf die Beschäftigung mit theologischen Subtilitäten, warnen vor leichtfertiger Auslegung der Heiligen Schrift und untersagen coniurationes, conventiones und conspirationes. Voraussetzungen für eine Duldung sind die Unterordnung unter das kirchliche Lehramt, der Gehorsam gegenüber der Hierarchie sowie die Einordnung in den örtlichen Pfarrverband. Erst nach Erfüllung dieser Auflagen kann - so das Konzil von Vienne ${ }^{72}$ - den honeste conversantes, domino in humilitatis spiritu deservientes gestattet werden, promissa continentia vel etiam non, die vita media zu führen, wobei man Begriffe verwandte, mit denen nicht nur die Möglichkeiten und Grenzen der semireligiosen Lebensweise markiert, sondern auch zentrale Themen der devoten Literatur des späten Mittelalters formuliert wurden ${ }^{73}$.

vervolging van de Vrijen van Geest, de Begijnen en Begarden, in: Nederlands Archief voor Kerkgeschiedenis 65 (1985) 120-138.

$71 \mathrm{~J}$. Tarrant, The Clementine Decrees on the Beguins. Conciliar and Papal Visions, in: Archivum Historiae Pontificiae 12 (1974) 300-308; J. Leclercq, Vienne (Geschichte der Ökumenischen Konzilien 8, Mainz 1965); L. Veerecke, La réforme de l'église au concile de Vienne 1311-1312, in: Studia moralia 14 (1976) 283-337; W. Janssen, Unbekannte Synodalstatuten der Kölner Erzbischöfe Heinrich von Virneburg (1306-1332) und Wolfram von Jülich (13321349), in: Annalen des Historischen Vereins vom Niederrhein 172 (1970) 113-154; A. Poloni, Synodale Gesetzgebung in der Kirchenprovinz Mainz - dargestellt an der Beginenfrage, in: Rottenburger Jahrbuch für Kirchengeschichte 5 (1986) 33-51; J. Greving, Protokoll über die Revision der Konvente der Beginen und Begarden zu Köln im Jahr 1452, in: Annalen des Historischen Vereins für den Niederrhein 73 (1902) 25-87; J. Asen, Die Beginen in Köln, in: ebd. 111 (1927) 81-180, 112 (1928) 71-148, 113 (1929) 13-96. Zusammenstellungen von $\mathrm{Be}-$ ginenordnungen aus den Niederlanden, Belgien und den Rheinlanden liegen in den folgenden ungedruckten Magisterarbeiten vor: $A$. van den Eynden, Statuten der begijnhoven van Mechelen, Brugge en het bisdom Luik (Löwen 1960); R. M. Quintijn, Normen en normering van het begijnenleven. Vergelijkende studie van begijnenregels in de Nederlanden van de XIII ${ }^{e}$ tot de XVIII e eeuw (Gent 1984); J. Knoppik, Hausordnungen rheinischer Beginengemeinschaften des 13. und 14. Jahrhunderts (FU Berlin 1992). Vgl. auch $A$. Pil, Een handleiding voor het geestelijk leven der Brusselse Begijnen, in: Sacris erudiri 16 (1965) 470-485; $A$. Schmidt, Tractatus contra hereticos Beckardos, Lullhardos et Swestriones des Wasmund von Hornburg, in: Archiv für mittelrheinische Kirchengeschichte 14 (1962) 336-386; A. G. Weiler, Begijnen en Begharden in de Spiegel van een universitair disput (Heidelberg 1458), in: Archief voor de Geschiedenis van de Katholieke Kerk in Nederland 12 (1968) 63-94.

72 Conciliorum Oecumenicorum Decreta, hrsg. von J. Alberigo u.a. (Basel, Barcelona, Freiburg, Rom, Wien 1962) $302 \mathrm{f}$.

73 Vgl. u.a.: N. Staubach, Pragmatische Schriftlichkeit im Bereich der Devotio moderna, in: Frühmittelalterliche Studien 25 (1991) 418-464; Th. Mertens, Boeken voor de eeuwigheid. Middelnederlandse geestelijk proza (Nederlandse literattuur en cultuur in de middeleeuwen 8, Amsterdam 1993); Th. Kock, Theorie und Praxis der Laienlektüre im Einflußbereich der Devotio moderna, in: Laienlektüre und Buchmarkt im späten Mittelalter (Gesellschaft, Kultur und Schrift. Mediävistische Beiträge 5, Frankfurt a.M., Berlin u.a. 1997) 199-220. 
Bestimmend für die restriktive Politik gegenüber dem Semireligiosentum war das vor allem in den Beschlüssen der Konzilien deutlich zum Ausdruck kommende Bestreben, die Entstehung nicht nur neuer Orden, sondern auch ordensähnlicher Vereinigungen zu unterbinden bzw. nur unter bestimmten Voraussetzungen zuzulassen. Das intendierte bereits 1139 das II. Laterankonzil, das den sanctimoniales die Befolgung entweder der Benediktiner- oder Augustinerregel vorschrieb, wurde auf dem III. und IV. Laterankonzil fortgeführt, auf denen man sich gegen „Auswüchse“ des Bruderschaftswesens wandte und für die Neugründung von Orden die Annahme der Regel und Institutionen der religiones approbati obligatorisch machte, und stand im Mittelpunkt der Beratungen des II. Konzils von Lyon $^{74}$.

Die auf ihm versammelten Väter untersagten 1274 angesichts des unübersehbar gewordenen Ordenswesens die Gründung neuer Orden und die Aufstellung anderer Regeln als der bewährten. Sie schrieben in der 23., später von Bonifaz VIII. in den Liber sextus aufgenommenen Konstitution Religionum diversitatem vor, daß die nach 1214 unter Mißachtung der Beschlüsse des IV. Laterankonzils gegründeten Bettelorden mit Ausnahme der Franziskaner und Dominikaner, später auch der Augustiner-Eremiten und Karmeliten abgeschafft werden sollten, und ließen neue Gemeinschaftsgründungen nur dann zu, wenn deren Mitglieder approbierte Regeln anzunehmen bereit seien ${ }^{75}$. Diese Bestimmungen gaben religiösen Gemeinschaften nur dann eine Existenzberechtigung, wenn sie sich entweder dem bestehenden Ordenswesen anpaßten oder aber auf die Wesensmerkmale der Vita religiosa - approbierte Regel, formelle Gelübde und das Ordensgewand verzichteten. Um den Widerspruch zwischen den Vorschriften des kirchlichen Rechts und der unübersehbaren Existenz eines religiösen Gemeinschaftslebens quasimonastischen Charakters juristisch zu überbrücken, schufen die Kanonisten eine Hilfskonstruktion, die den nichtregulierten religiösen Gemeinschaften und ihnen vergleichbaren Genossenschaften rechtliche Sicherheit geben sollte. Dabei griffen sie nicht nur auf das Dekret und die Dekretalien, sondern auch auf das Römische Recht, genauer auf das Vereinsrecht, zurück, indem sie die semireligiösen Gemeinschaften als societates omnium bonorum definierten ${ }^{76}$. Diese im 47 . Buch

74 Conciliorum Oecumenicorum Decreta (wie Anm. 72) 75, $192 \mathrm{f}$.

75 Ebd., 218; B. Roberg, Das zweite Konzil von Lyon 1274 (Konziliengeschichte A: Darstellungen, Paderborn 1990) 89-126; St. Kuttner, Conciliar Law in the Making. The Lyonese Constitutions (1274) of Gregor X in a Manuscript at Washington, in: Miscellanea Pio Paschini. Studi di Storia Ecclesiastica (Lateranum NS 15, Rom 1949) II, 39; R. M. Emery, The Second Council of Lyon and the Mendicant Orders, in: Catholic Historical Review 39 (1953) 257-271; Elm, Ausbreitung, Wirksamkeit und Ende der provençalischen Sackbrüder (wie Anm. 47).

76 Sinibaldus Fliscus, Super libros quinque decretalium (Frankfurt 1570, ND 1968) 75 f.; ders., In primum decretalium librum (Venedig 1589, ND 1965) 159; Johannes Andreae, In quintum Decretalium librum novella commentaria (Venedig 1581, ND 1963) $95 \mathrm{f}$.; Bernardus Papiensis, Summa decretalium (Regensburg 1866) 109f.; M. Waltzing, Etude historique sur les corporations professionelles chez les Romains depuis les origines jusqu'à la chute de l'empire d'Occident I-II (Löwen 1894-96); P. Gillet, La personalité juridique en droit ecclésiastique 
der Digesten genauer beschriebene societas war eine Besitz- und Erwerbsgemeinschaft, die im Unterschied zu collegium und corpus keiner öffentlichen Approbation bedurfte. Sie hatte zwar nicht den Charakter einer juristischen Person, war aber dennoch nicht dem Verdikt der Illegalität verfallen, was schon die vorkonstantinischen Christen nützten, um sich und ihren Gemeinden wenn nicht Anerkennung, dann doch Duldung zu sichern. Auf den status medius übertragen bedeutete dies, daß die ihm angehörenden Personen und Gemeinschaften bei Beachtung der für die societas geltenden Vorschriften einen Rechtscharakter erhielten, der sie nicht mit den als corpus oder collegium geltenden Kloster- und Ordensgemeinschaften gleichstellte, sie jedoch davor bewahrte, als domus illicitae, ordines non approbati oder gar conventicula haeretica eingestuft zu werden. Im Rückgriff auf ältere kirchenrechtliche Bestimmungen, vor allem aber ausgehend von den Digesten entwickelten die Kanonisten so für die vita media eine Rechtsfigur, die bereits im 14. Jahrhundert von den Verteidigern der Beginen, Begarden und Tertiaren zur Grundlage ihrer Argumentation gemacht ${ }^{77}$ und von den Apologeten der Fratres vitae communis in zahlreichen juristischen Gutachten gestützt, ausgebaut und so präzisiert wurde ${ }^{78}$, daß sie ein Jahrhundert später von der Socie-

spécialement chez les décretistes et les décretalistes et dans le code de droit canonique (Malines 1927); F. Wieacker, Societas. Handelsgenossenschaft und Erwerbsgemeinschaft (Weimar 1931); F. M. de Robertis, Storia delle corporazioni e del regime associatio nel mondo romano I-II (Bari 1973); ders., Dai „collegia cultorum“ alle "confraternitates" religiose: la normativa Giustiniana sui tenuiores e la sua disapplicazione nella età di mezzo, in: Confraternite, Chiese e Società (wie Anm. 35) 11-29. Vgl. in diesem Zusammenhang auch: H. E. Feine, Vom Fortleben des römischen Rechts in der Kirche, in: Zeitschrift der SavignyStiftung für Rechtsgeschichte 73, Kan. Abt. 42 (1956) 1-24.

77 Neben der in den Anm. 28 und 48 genannten Literatur zum „Beginenstreit“: M. D'Alatri, Contrasti tra Penitenti francescani ed autorità ecclesiastica nel Trecento, in: I frati Penitenti (wie Anm. 28), 101-110; A. G. Matanic, Il „Defensorium Tertii Ordinis beati Francisci“ di San Giovanni de Capestrano, in: Il movimenti francescano della penitenza (wie Anm. 28), 47-57.

78 L. Korth, Die ältesten Gutachten über die Bruderschaft des gemeinsamen Lebens, in: Mitteilungen aus dem Stadtarchiv von Köln 5 (1888) 1-27; H. Keussen, Der Dominikaner Matthäus Grabow und die Brüder vom Gemeinsamen Leben, in: ebd. 29-47; D. de Man, Vervolging, welke de broeders en zusters des gemeenen levens te verduren hadden, in: Bijdragen voor vaderlandse Geschiedenis en Oudheidkunde 6 (1926) 283-295; C. H. Lambermond, Geert Grote, zijn stichtingen en zijn bestrijders, in: Studiën 73 (1941) 187-200; St. Wachter, Matthias Grabow, ein Gegner der Brüder vom Gemeinsamen Leben, in: Festschrift zum 50jährigen Bestandsjubiläum des Missionshauses St. Gabriel Wien-Mödling (Sankt Gabrieler Studien VIII, Wien-Mödling 1939) 289-376; G. van den Heuvel, Het bestaansrecht van de Broeders van het Gemene Leven vóór de bisschoppelijke goedkeuring van 1401 (Pontificia Universitas Gregoriana Romae, Dissertatio, Tilburg 1953); G. Biel, Tractatus de communi vita clericorum, hrsg. von W. M. Landeen, in: Research Studies of the State College of Washington 28 (1960) 79-95. Vgl. dazu: I. Crusius, Gabriel Biel und die oberdeutschen Stifte der Devotio moderna (wie Anm. 63), 298-322; G. Faix, Gabriel Biel und die Brüder vom Gemeinsamen Leben. Quellen und Untersuchungen zu Verfassung und Selbstverständnis des oberdeutschen Generalkapitels (Spätmittelalter und Reformation 11, Tübingen 1998); W. Lourdaux, Dirk of Herxen's Tract De utilitate monachorum: A Defence of the Lifestyle of the Brethren and Sisters of the Common Life, in: Pascua Mediaevalia. Studies voor Prof. Dr. J. M. De Smet (Mediaevalia Lovaniensia I, 10, Löwen 1983) 312-336; ders., De utilitate mo- 
tas Jesu und den übrigen Regularklerikervereinigungen und Säkularinstituten übernommen werden konnte. ${ }^{79}$ Die rechtliche Eigenart der vita media als Stand zwischen Kloster und Welt, wie sie sich in den zahlreichen zugunsten der Brüder vom Gemeinsamen Leben verfaßten Verteidigungsschriften - mit besonderer Deutlichkeit im Defensorium des Gerard Zerbolt von Zutphen ${ }^{80}$ - darstellt, läßt sich am besten durch den Vergleich mit der Rechtsordnung des Klosters bzw. Ordenshauses im eigentlichen Sinne, der domus religiosa, verdeutlichen. Die auf das Gehorsamsgelübde gegründete, von der maior et sanior pars übertragene und durch kirchliche Approbation bestätigte Amtsgewalt der Prioren, Äbte und Pröpste findet in der societas keine Entsprechung. Nach dem für sie geltenden Prinzip, par in parem non habet potestatem, entbehrt der an der Spitze der societas stehende Superior einer eigentlichen Jurisdiktionsgewalt. Ähnliches gilt für den Rechtscharakter der societas selbst. Ex definitione nicht zur Mehrheitsbildung fähig, können ihre Angehörigen keine verbindlichen Beschlüsse fassen. Was für den Rektor und die societas gilt, trifft auch für die consuetudines zu. Es handelt sich bei ihnen nicht um rechtsverbindliche Regeln, sondern um private Hausordnungen, Statuten oder Proposita, die ihre Verbindlichkeit aus dem allgemeinen Recht und den für alle Christen geltenden Anordnungen des Evangeliums bzw. Kirchenrechts ableiten. Wenn dennoch Anordnungen ergehen und Mehrheitsbeschlüsse gefaßt werden, handelt es sich nicht um Befehle oder Festsetzungen mit vis coactiva, sondern um consilia und correctiones fraternae, die nicht ex necessitate, sondern nur ex caritate et amicitia befolgt werden. Es entspricht diesen Gegebenheiten, wenn beim Beginn der nichtregularen communis vita keine rechtsverbindli-

nachorum van Dirk van Herxen. Een verdediging van de Moderne Devoten tegenover de burgerlijke overheid, in: Ons geestelijk Erf 59 (1985) 185-196; A. Beriger, Ruotger Sycamber van Venray: Rede zum Lob der Brüder vom Gemeinsamen Leben 1501, in: Ons geestelijk Erf 68 (1994) 129-143. Zur Entstehung der Bruderschaft vgl. u.a.: C. van der Wansem, Het ontstaan en de geschiedenis der broedershap van het gemene leven tot 1400 (Universiteit te Leuven. Publicaties op het gebied der geschiedenis en der philologie IV, 12, Löwen 1958); W. Lourdaux, De Broeders van het gemene Leven, in: Bijdragen. Tijdschrift voor filosofie en theologie 33 (1972) 373-416. Elm, Die Bruderschaft vom gemeinsamen Leben (wie Anm. 16). 79 G. Switek, Die Eigenart der Gesellschaft Jesu im Vergleich zu den anderen Orden in der Sicht des Ignatius und seiner ersten Gefährten, in: Ignatianisch. Eigenart und Methode der Gesellschaft Jesu, hrsg. von M. Sievernich, G. Switek (Freiburg 1991) 204-232; J. W. O'Malley, The First Jesuits (Cambridge MA 1993). Vgl. auch: O. Steggink, De Moderne Devotie in het Montserrat van Ignatius van Loyola, in: Ons gestelijk Erf 59 (1985) 383-392.

80 A. Hyma, Het traktaat "Super modo vivendi devotorum hominum simul commorantium" door Gerard Zerbolt van Zutphen, in: Archief voor Geschiedenis van het Aartsbisdom Utrecht 52 (1926) 1-100; ders., Is Gerard Zebolt of Zutphen the Author of the „Super modo vivendi“?, in: Nederlands Archief voor Kerkgeschiedenis NS 16 (1921) 107-128; J. Deschamps, Middelnederlandse vertalingen van Super modo vivendi (7de hoofdstuk) en De libris teutonicalibus van Gerard Zerbolt van Zutphen, in: Handelingen. Koninklijke Zuidnederlandse Maatschappij voor Taal- en Letterkunde en Geschiedenis 14 (1960) 67-108, 15 (1961) 175-220; N. Staubach, Gerhard Zerbolt von Zutphen und die Apologie der Laienlektüre in der Devotio moderna, in: Theorie und Praxis der Devotio moderna (wie Anm.) 221289. Vgl. auch: G. H. Gerrits, Inter timorem et spem. A Study of the Theological Thought of Gerard Zerbolt of Zutphen (Studies in Medieval and Reformation Thought 37, Leiden 1986). 
chen Verpflichtungen in der Form einer professio verlangt werden. Am Anfang des Gemeinschaftslebens steht daher lediglich eine receptio, die nur partielle Bereitschaft zur Befolgung der tria substantialia des Ordenslebens, d.h. zur Aufgabe des eigenen Besitzes, zur Beschränkung der persönlichen Freiheit und zur Bewahrung der Keuschheit, zur Voraussetzung hat. Die Gegensätze von Kloster- und Bruderschaft sind zahlreich. Sie lassen sich an mehr als einem Beispiel aufzeigen. Will man statt weiterer Explikationen die rechtlichen Unterschiede zwischen den beiden Gemeinschaftsformen schlagwortartig zusammenfassen, bieten sich dafür die in der Literatur des 14. und 15. Jahrhunderts bei der Definition und Verteidigung der Lebensweise der Beginen, Tertiaren, Fraterherren und Süsteren immer wieder verwandten, einerseits für ,anstaltsartige Institutionen“ und andererseits für „brüderlich-genossenschaftliche Gemeinschaften“ konstitutiven Begriffe subordinatio und aequalitas, potestas und caritas, obedientia und libertas als besonders geeignet $\mathrm{an}^{81}$.

\section{V.}

Die Beschreibung dessen, was man das Selbstverständnis des status tertius nennen könnte, setzt die Auswertung eines breiten, sehr heterogenen Quellenmaterials voraus, das von Urkunden und Statuten über literarische und liturgische Texte bis zu den Werken der bildenden Kunst und Musik reicht. Zu den Artikulationsformen dieses Selbstverständnisses gehört der Bezug auf die Gestalten und Gemeinschaften, auf die sich die Semireligiosen des hohen und späten Mittelalters als ihre Vorläufer und Vorbilder beriefen ${ }^{82}$. Das Arsenal dieser Prototypen geht

${ }^{81} J$. Ratzinger, Die christliche Brüderlichkeit (München 1960); J. Hasenfuß, Brüderlichkeit in religionssoziologisch-theologischer Sicht, in: Wahrheit und Verkündigung. Michael Schmaus zum 70. Geburtstag, hrsg. von L. Scheffczyk (München 1967) 265-283; W. Schieder, Brüderlichkeit, Bruderschaft, Brüderschaft, Verbrüderung, Bruderliebe, in: Geschichtliche Grundbegriffe Bd. 1, hrsg. von O. Brunner, W. Conze, R. Kossellek (Tübingen 1972) $552-$ $581 ; M$. D. Chenu, „Fraternitas“. Evangile et condition socio-culturelle, in: Revue d'histoire de la spiritualité 49 (1973) 385-400; H. Tyrell, Die christliche Brüderlichkeit - Semantische Kontinuitäten und Diskontinuitäten, in: Festschrift für F. X. Kaufmann (im Druck).

82 Einen Überblick gibt: S. Gieben, Appunti per l'iconografia dei santi e beati dell'Ordine della Penitenza (secoli XIII-XIV), in: I fratri penitenti di San Francesco (wie Anm. 28), 111-124. Ergänzungen: K. Klein, Frühchristliche Eremiten im Spätmittelalter und in der Reformationszeit, in: Literatur und Laienbildung im Spätmittelalter und in der Reformationszeit, hrsg. von L. Grenzmann, K. Stackmann (Stuttgart 1984) 686-695; J. Oliver, „Gothic“ Women and Merovingian Desert Mothers, in: Gesta 32 (1993) 124-134; E. Gössmann, Mariologische Entwicklungen im Mittelalter. Frauenfreundliche und frauenfeindliche Aspekte, in: Maria - für alle Frauen oder über allen Frauen?, hrsg. von E. Gössmann, D. R. Bauer (Freiburg 1989) 63-85; M. Webrli-Jones, Haushälterinnen Gottes. Zur Mariennachfolge der Beginen, in: Maria - Abbild oder Vorbild? Zur Sozialgeschichte mittelalterlicher Marienverehrung, hrsg. von H. Röckelein (Tübingen 1990) 147-182; H. M. Garth, Saint Mary Magdalene in Medieval Literature (John Hopkins University Studies, Baltimore 1950); V. Saxer, Le culte de Marie-Madeleine en occident dès origines à la fin du moyen âge (Auxerre, Paris 1959); S. Haskins, Mary Magdalen. Myth and Metapher (London 1993); K. L. Jansen, Mary Magda- 
bis ins frühe Mittelalter, ja bis ins christliche Altertum und das biblische Zeitalter zurück: Elias, Antonius und Paulus von Theben als die Archetypen der vita eremitica, Johannes der Almosengeber und Nikolaus von Myra, die Helfer der Armen und Benachteiligten, Alexius und Rochus, die Repräsentanten und zugleich Patrone der Kranken und Leidenden, der Gefallenen und Strauchelnden, Elisabeth von Ungarn, die Landgräfin von Thüringen, und Ludwig IX., der heilige König von Frankreich, die Exponenten christlicher caritas und intensiver Laienfrömmigkeit, die um das Wohl der familia sacra in Bethanien bemühte Martha, Maria Magdalena, das Vorbild und der Inbegriff der Buße, Maria, die mater dolorosa iuxta crucem, und Christus, der dornengekrönte Leidensmann.

Die Semireligiosen - in besonderem Maße die Brüder vom Gemeinsamen Leben - sahen sich und ihre Gemeinschaft vorgebildet in Benjamin, dem jüngsten Sohn Jakobs, in Bethlehem, der geringsten unter den Fürstenstädten Judäas, und in Paulus, dem letzten Apostel: Präfigurationen, die sicherlich als freiwillige oder erzwungene Bescheidenheitsäußerungen einer mehr oder minder gebildeten, im Gefüge sowohl der profanen als auch der sakralen Gesellschaft überwiegend periphär angesiedelten Personengruppe verstanden werden müssen, die aber ähnlich wie die Selbstbezeichnung der Päpste als „Diener der Diener Gottes“ den Anspruch auf Vorrang, wenn nicht gar auf eine Spitzenstellung unter den „Istituti di perfezione" implizierten. Ein solcher Anspruch wurde nur selten von den Brüdern selbst expressis verbis erhoben, auch wenn man ihn in allen Äußerungen, ja in der gewissermaßen provokatorischen Existenz der Semireligiosen handgreiflich zu spüren vermag. Wortwörtlich wurde er in der Mitte des 15. Jahrhunderts von dem Franziskanerobservanten Johannes Brugman formuliert. In Anknüpfung an Joachim von Fiore sah er in der Gemeinschaft der Brüder vom Gemeinsamen Leben den Geistesorden, der das dritte Zeitalter der Welt- und Heilsgeschichte einleiten sollte, und daher als allen anderen Orden an spirituellem Gehalt überlegen gelten konnte ${ }^{83}$.

Der eschatologische Ausblick Brugmans interessiert hier weniger als der Versuch der Fraterherren und deren Gesinnungsfreunde, ihren modus vivendi historisch zu verankern. Sie verwiesen auf die frühchristlichen Asketen in Rom, auf Aquila und Priscilla, die im Korinther- und Römerbrief erwähnten Gehilfen des Apostels Paulus. Sie sahen ihre eigene societas vorweggenommen in dem Freundeskreis Augustins auf dem Landgut Cassiciacum zwischen Mailand und Bergamo und in der Sacra familia, die Hieronymus in Bethlehem um sich versammelte. Die frühchristlichen Eremiten Ägyptens, Syriens und Palästinas, Elias und Elisäus, die Propheten des Alten Testamentes und die frommen Essener waren für

len and the Mendicants: The Preaching of Penance in the Late Middle Ages, in: Journal of Medieval History 21 (1995) 1-25; G. Constable, Three Studies in Medieval Religious and Social Thought. The Interpretation of Mary and Martha. The Ideal of the Imitation of Christ. The Orders of Society (Cambridge 1995); Die Passion Christi in Literatur und Kunst des Spätmittelalters, hrsg. von W. Haug, B. Wachinger (Fortuna Vitrea 12, Tübingen 1993).

${ }_{83} \mathrm{~J}$. Brugman, Speculum imperfectionis, hrsg. von F.A.H. van den Homberg (Groningen 1962). 
sie nicht mehr die Prototypen der Mönche und des Mönchtums, sondern Schöpfer freier societates, die sine regula, sine statutis oboedientialibus, sine habitu approbato aut ceremoniis regularibus lebten. Das eigentliche Vorbild waren jedoch weder die Kirchenväter noch die Propheten und Eremiten, sondern die vita apostolica und die ecclesia primitiva. Was schon Mönche, Kanoniker und Mendikanten, ja selbst die Ritterorden für sich beansprucht hatten, nämlich nach Art der Apostel zu leben und die Urkirche zu erneuern, behaupteten die Semireligiosen mit ähnlicher Ausschließlichkeit wie die übrigen Orden und Ordenszöten von sich selbst ${ }^{84}$. Mit Argumenten, die schon von den apostolischen Wanderpredigern des 12. Jahrhunderts verwandt und von Jakob von Vitry in der von ihm verfaßten Vita der Maria von Oignies zur Rechtfertigung des Beginenstandes herangezogen wurden ${ }^{85}$, vertraten auch die Fraterherren den Anspruch, eine direkte, wenn nicht gar die einzig legitime Fortsetzung der apostolischen Urgemeinde zu sein. Wie diese folgten sie keiner anderen Regel als der regula evangelii, waren sie keinem anderen Superior als dem abbas Jesus Christus verpflichtet. Während sich die Mönche und Kanoniker auf Benedikt und Augustinus und die Franziskaner und Dominikaner auf Franz und Dominikus als ihre fundatores beriefen, hatten sie keinen anderen Stifter als den Herrn selbst. Ein Anspruch, der die bereits von Geert Grote gezogene Konsequenz einschloß ${ }^{86}$, daß die Regeln Augustins, Benedikts und Franz von Assisi als überflüssig erscheinen und die von ihnen gestifteten Orden als particularitates et singularitates, also als Hindernisse auf dem Weg zur wahren vita christiana, empfunden werden konnten. Was in den devoten Schriften nur anklingt, wird in den vọn den Fraterherren und ihren Freunden und Förderern verfaßten Verteidigungsschriften deutlich und unmißverständlich zum Ausdruck gebracht. Unter dem von Klerus, Episkopat und Kurie ausgehenden Druck, sich zumindest in ihrer äußeren Form den Normen des Mönchs- oder Kanonikertums anzupassen oder gar auf die Eigenart ihrer semireligiosen Lebensweise ganz zu verzichten, reagierten sie mit einer Entschiedenheit, die unmißverständlich zu erkennen gab, daß sie ihrer durch Gleichheit, Freiheit und brüderliche Liebe gekennzeichneten Lebensform einen höheren Rang zuerkannten als dem auf Bindung und Gehorsam gegründeten Ordensleben. Auf diese Würde zu

${ }^{84}$ M.-H. Vicaire, L'imitation des apôtres: Moines, chanoines, mendiants, IVe-XIIIe siècles (Paris 1963); G. Olsen, The Idea of the Ecclesia Primitiva in the Writings of Twelfth-Century Canonists, in: Traditio 25 (1969) 61-86; G. Leff, The Apostolic Ideal in Later Medieval Ecclesiology, in: Journal of Theological Studies 18 (1967) 58-82; S. H. Hendrix, In Quest of the Vera Ecclesia: the Crisis of Late Medieval Ecclesiology, in: Viator 7 (1976) 347-378; A. Vauchez, La Bible dans les confréries et les mouvements de dévotion, in: Le Moyen Age et la Bible, hrsg. von R. Riché, G. Lobrichen (Bible de tous les temps, Paris 1984) 583-595; Constable, Three Studies (wie Anm. 82).

85 Neben der in Anm. 46 genannten Lit.: J. Becquet, L'Institution. Premier coutumiers de l'Ordre de Grandmont, in: Revue Mabillon 46 (1956) 15-32; Vita b. Mariae Oigniacensis, in: Acta Sanctorum V (Antwerpen 1867) 547-575. Vgl. auch Lettres de Jacques de Vitry (1160/ 1170-1240) évêque de Saint-Jean-d'Acre. Edition critique, hrsg. von $R$. B. C. Huygens (Leiden 1960) 71-78.

86 G. Groote, De Simonia ad beguttas, hrsg. von W. de Vreese (Den Haag 1940) 29. 
verzichten und eine Regel anzunehmen, erschien ihnen als nichts anderes, quam vendere libertatem nostram, singulare decus christianae religionis et emere vincula et carceres, wie es 1490 Peter Dieburg, der Rektor des Hildesheimer Fraterherrenhauses zum Lüchtenhof, in seinen Annales formuliert ${ }^{87}$. Die semireligiose Lebensform war für ihn und seine gleichgesinnten Brüder nicht mehr wie für die Dekretisten und Dekretalisten ein Notbehelf und wie für den Klerus eine "quantité négligeable“, sondern eine konsequente, ja die einzig richtige Nachfolge Christi. Formulierungen wie die Peter Dieburgs deuten aber noch weitergehende Konsequenzen an. Mit der Gleichsetzung von Bruderleben und christlicher Freiheit wird dem regulierten Ordensleben, wie es sich im späten Mittelalter verstand, seine Grundlage entzogen. Wo, um eine Formulierung von Geert Grote aufzugreifen, „volkomen mynne" und „volkomen anhangen an god" zu den allein relevanten Voraussetzungen für die vita perfecta gemacht wurden ${ }^{88}$, verloren nicht nur die Äußerlichkeiten des Ordenslebens, der habitus, die tonsura und die cappa, ihre Bedeutung, da zerbrach auch der Grundstein des Mönchtums, nämlich die Gelübde, deren Ablegung in der spätmittelalterlichen Mönchstheologie als zweite Taufe, als ein die ewige Seeligkeit garantierender Akt verstanden wurde ${ }^{89}$. Wo ohne Approbation durch Papst oder Bischof und außerhalb des Klosters ein Ordensleben reiner Gesinnung geführt werden konnte, da war die vita perfecta nicht mehr nur Sache einer rechtlich fixierten Institution, da waren sowohl die vita regularis als auch die vita media überflüssig, da galt schon die von Wyclif praeludierte erasmische Gleichung purus christianus verus monachus ${ }^{90}$. Daß eine solch konsequente Auslegung des Fraterherrenideals und damit die Absolutsetzung des status medius an die Grundlagen des mittelalterlichen Mönchtums rührte, ja die im späten Mittelalter vorherrschende Auffassung vom Wesen der Kirche in Frage stellte, ist nicht bloß die Interpretation rückschauender Historiker. Martin Luther hat selbst ungeachtet der von ihm heftig kritisierten Auswüchse des profanen Bruderschaftswesens und der grundsätzlichen Ablehnung

87 Annalen und Akten der Brüder des gemeinsamen Leben im Lüchtenhof zu Hildesheim, hrsg. von $R$. Doebner (Quellen und Darstellungen zur Geschichte Niedersachsens 9, Hannover, Leipzig 1903) 113. Über Dieburg: G. Boerner, Die Annalen und Akten der Brüder des gemeinsamen Lebens im Lüchtenhof zu Hildesheim. Eine Grundlage der Geschichte der deutschen Brüderhäuser und ein Beitrag zur Vorgeschichte der Reformation (Fürstenwalde 1905); W. Schültke, Die Brüder vom gemeinsamen Leben und Peter Dieburg, 1420-1494 (Diss. theol. Rostock 1969). Vgl. auch: E. Barnikol, Bruder Dieburgs deutsches Christentum und Luthers Stellung zu den Brüdern vom gemeinsamen Leben, in: Das Eisleber Lutherbuch, hrsg. von H. Etzrod, K. Kronenberg, (Magdeburg 1933) 18-28.

88 S. Anm. 86.

89 B. Lohse, Mönchtum und Reformation. Luthers Auseinandersetzung mit dem Mönchsideal des Mittelalters (Forschungen zur Kirchen- und Dogmengeschichte 12, Göttingen 1963) $167-170$.

90 Fifty Heresies and Errors of Friars, in: Selected English Works of John Wyclif, hrsg. von Th. Arnold (London 1869-71) III, 367-72; A. Dakin, Die Beziehung John Wyclifs und der Lollarden zu den Bettelmönchen (London 1911); Th. Renna, Wyclif's Attacks on the Monks, in: From Ockham to Wyclif, hrsg. von A. Hudson, M. Wolks (Studies in Church History. Subsidia 5, New York 1987) 267-280. 
des Ordensstandes ${ }^{91}$ die innere Verwandtschaft zwischen der neuen Lehre und dem alten Institut erkannt. Als ihn 1532 die durch die Attacken der zu Prädikanten des neuen Glaubens gewordenen Augustiner-Eremiten beunruhigten Herforder Fraterherren um die Begutachtung ihres Lebens baten, lobte er nicht nur ihre ratio vivendi und ihr genus vitae, da bestätigte er auch, daß in der Beschreibung ihres Lebens vom neuen Verständnis des Glaubens her nichts Unrechtes gefunden werden könne, da sie ja ohne Ablegung der von ihm als unchristlich verurteilten Gelübde ein Leben im Sinne des Evangeliums führten, was Philipp Melanchthon mit dem Terminus wiederholte, mit dem schon im 13. und 14. Jahrhundert Vertreter und Verfechter des status tertius die besondere Stellung dieses Standes zwischen Kloster und Welt, zwischen Ordensleuten und Laien, beschrieben und als rechtskonform bezeichnet hatten: hanc societatem esse rem licitam ${ }^{92}$.

\section{VI.}

Die Frage, welche Rolle die vita regularis sine regula beim Übergang vom Spätmittelalter zur Reformation und bei der ihr folgenden Konfessionalisierung spielte, wurde bisher weder explizit gestellt noch auf systematische Weise zu beantworten versucht ${ }^{93}$. Das Problem selbst war aber dennoch bereits im 19. Jahr-

${ }^{91}$ H.-Chr. Rublack, Zur Rezeption von Luthers De votis monasticis iudicium, in: Reform und Revolution. Beiträge zum politischen Wandel und den sozialen Kräften am Beginn der Neuzeit. Festschrift R. Wohlfeil zum 60. Geburtstag, hrsg. von R. Postel, F. Kopitzsch (Stuttgart 1989) 224-237; Lobse, Mönchtum und Reformation (wie Anm. 89); O. H. Pesch, Luthers Kritik am Mönchtum in katholischer Sicht, in: Strukturen christlicher Existenz. Beiträge zur Erneuerung des geistlichen Lebens, hrsg. von $H$. Schlier u.a. (Würzburg 1968) 81-97; H.-M. Stamm, Luthers Stellung zum Ordensleben, in: Der Durchbruch der reformatorischen Erkenntnis bei Luther. Neuere Untersuchungen, hrsg. von $B$. Lobse (Veröffentlichungen des Instituts für Europäische Geschichte Mainz. Abt. für Abendländische Religionsgeschichte 101, Wiesbaden 1980); W. Werbeck, Martin Luthers Widmungsrede zu „De votis monasticis", in: Luther 62 (1991) 78-89. Zu Luthers Kritik an den "weltlichen“ Bruderschaften zuletzt: $B$. Schneider, Wandel und Beharrung. Bruderschaften und Frömmigkeit in Spätmittelalter und Früher Neuzeit, in: Volksfrömmigkeit in der Frühen Neuzeit, hrsg. von $H$. Molitor, H. Smolinski (Katholisches Leben und Kirchenreform im Zeitalter der Glaubensspaltung 54, Münster 1994) 65-87.

92 Das Fraterherrenhaus zu Herford II: Statuten, Bekenntnisse, Briefwechsel, hrsg. von R. Stupperich (Veröffentlichungen der Historischen Kommission von Westfalen 35, Münster 1984); R. Stupperich, Luther und das Fraterhaus in Herford, in: Geist und Geschichte der Reformation. Festgabe H. Rückert zum 65. Geburtstag (Arbeiten zur Kirchengeschichte 38, Berlin 1966) 219-238; ders., Das Herforder Fraterherrenhaus und die Reformation, in: Jahrbuch für Westfälische Kirchengeschichte 64 (1971) 7-27.

93 Als Beispiel für Einzelstudien: $F$. Merzbacher, Die Aschaffenburger Beginen um das Jahr 1527, in: Archiv für mittelrheinische Kirchengeschichte 3 (1951) 365-368; J.-Ch. Schmitt, Les dernières années d'un beguinage colmarien d'après ses comptes (1510-1531), in: Annuaire de la Société d'Histoire et d'Archéologie de Colmar (1975/76) 31-41; F. Glauser, Das Schwesternhaus zu St. Anna im Bruch in Luzern 1498-1625. Religiöse, soziale und wirtschaftliche 
hundert ähnlich aktuell wie in der jüngsten Vergangenheit, wenn auch aus anderen Motiven als denjenigen, die für die heutige Forschung bestimmend sind. Wenn sich die am Ende des 19. und zu Beginn des 20. Jahrhunderts besonders intensive Beschäftigung von Sozialwissenschaftlern und Rechtshistorikern mit dem mittelalterlichen Genossenschaftswesen auch auf das Semireligiosentum erstreckte, geschah dies, wie vor allem Otto von Gierkes Werk erkennen läßt, wegen seines vermuteten Beitrages zu jenem Prozeß der Republikanisierung des Staates und der Demokratisierung der Gesellschaft, den die Historiker des 19. Jahrhunderts nicht als ein lediglich historisches Phänomen, sondern als ein in ihrer eigenen Gegenwart höchst aktuelles Problem empfanden ${ }^{94}$. Dieser Zeitbezug galt in noch höherem Maße für die vom Kulturkampf geprägte kirchengeschichtliche Forschung, der es bei der Beschäftigung mit dem Semireligiosentum um die Frage nach dessen Vorläuferrolle für die Reformation ging. Für Carl Ullmann, der die bereits von der frühen reformatorischen Historiographie aufgeworfene Frage nach den Reformatoren vor der Reformation auf eindeutige Weise glaubte beantworten zu können, waren die „freien religiösen“ Vereinigungen nichts anderes als Zusammenschlüsse von Gläubigen, die sich, wie schon Flaccus Illyricus und Gottfried Arnold meinten, als Zeugen des Evangeliums bewährt hatten, wofür ihm und den in seinem Sinne argumentierenden Historikern die Devotio moderna als Wegbereiterin sowohl des Humanismus als auch der Reformation ein beweiskräftiges Argument lieferte ${ }^{95}$. Von der Auffassung, daß dem für das Spätmittelalter als charakteristisch

Strukturveränderungen einer Beginengemeinschaft auf dem Weg vom Spätmittelalter zur Katholischen Reform (Luzerner Historische Veröffentlichungen 22, Luzern, Stuttgart 1987). 94 O. Gierke, Deutsches Genossenschaftsrecht I: Rechtsgeschichte der deutschen Gemeinschaft (Berlin 1868); E. W. Böckenförde, Die deutsche verfassungsgeschichtliche Forschung im 19. Jahrhundert. Zeitgebundene Fragestellungen und Zeitbilder (Schriften zur Verfassungsgeschichte I, Berlin 1961); O. G. Oexle, Otto von Gierkes „Rechtsgeschichte der deutschen Genossenschaft". Ein Versuch wissenschaftsgeschichtlicher Rekapitulation, in: Deutsche Geschichtswissenschaft um 1900, hrsg. von N. Hammerstein (Stuttgart 1988)193-217; $P$. Landau, Otto Gierke und das kanonische Recht, in: Die deutsche Rechtsgeschichte in der NS-Zeit, ihre Vorgeschichte und Nachwirkungen, hrsg. von J. Rückert, D. Willoweit (Beiträge zur Rechtsgeschichte des 20. Jahrhunderts 12, Tübingen 1995) 94-97.

95 C. Ullmann, Reformatoren vor der Reformation II: Die positiven Grundlagen der Reformation auf dem populären und wissenschaftlichen Gebiete (Gotha 21866). Zum Problem: $H$. A. Oberman, Werden und Wertung der Reformation. Vom Wegstreit zum Glaubenskampf (Spätscholastik und Reformation II, Tübingen 1977); ders., Forerunners of the Reformation. The Shape of Late Medieval Thought (Philadelphia 1981); Albert Hyma, The Christian Renaissance. A History of the "Devotio Moderna“ (Hamden, Conn. 21965); L. E. Halkin, La „Devotio Moderna“ et les origines de la Réforme aux Pays-Bas, in: Courants religieux et humanisme à la fin du XVe et au début du XVIe siècle. Colloque de Strasbourg 9-11 mai 1957 (Travaux du Centre d'histoire des religions de Strasbourg, Paris 1959) 45-51; J. Roelink, Moderne Devotie en Reformatie, in: Serta Historica 2 (1970) 5-43; W. Lourdaux, Dévotion moderne et humanisme chrétien, in: The Late Middle Ages and the Dawn of Humanism outside Italy. Proceedings of the International Conference, Louvain, May 11-13, 1970 (Mediaevalia Lovaniensia I, 1, Löwen, Den Haag 1972) 57-77; R. Mokrosch, Devotio moderna II: Verhältnis zu Humanismus und Reformation, in: Theologische Realenzyklopädie VIII. (1981) 609-617; N. Staubach, Christianam sectam arripere. Devotio moderna und Humanismus zwischen Zirkelbildung und gesellschaftlicher Integration, in: Europäische So- 
angesehenen Semireligiosentum ein veränderndes, emanzipatorisches, reformerisches, präreformerisches, ja reformatorisches Potential innewohnte, gehen auch die Interpretationen aus, die in der "monastisch geprägten“ Laienfrömmigkeit eine der Voraussetzungen für den aus der „protestantischen Ethik“ hervorgehenden "Geist des Kapitalismus" sahen"6 oder umgekehrt wie in der Häresie so auch im Semireligiosentum den Zusammenschluß jener Kräfte glaubten erkennen zu können, die sich gegen die „feudalen Mächte“ wandten, die „frühbürgerliche Revolution" initiierten ${ }^{97}$ sowie dem modernen Individualismus und der Frauenemanzipation den Weg bereiteten ${ }^{98}$. Diesem Deutungsmuster sind Gennaro M. Monti, Gabriel Le Bras, Giles G. Meersseman, André Vauchez und die meisten anderen Vertreter der jüngeren Bruderschafts- und Semireligiosenforschung mit dem schon von Max Weber verwandten Argument entgegengetreten, daß dieser Stand wesentlich zur Intensivierung des kirchlichen Einflusses auf die Laien und die "Profangesellschaft" beigetragen habe und daher als Zeugnis für die zunehmende "sociabilite“" und „christianisation" der europäischen Gesellschaft gelten könne, also keineswegs a priori systemsprengender Natur gewesen sei und deswegen auch nicht ohne weiteres als einer der Faktoren angesehen werden könne, die den von den Vorreformen zur Reformation führenden Prozeß in Gang gesetzt oder beschleunigt hätten'9 . Diese Argumentation wird durch die Tatsache gestützt, daß das mittelalterliche Semireligiosentum ähnlich wie das Ordenswesen

zietätsbewegung und demokratische Tradition. Bürgerlich-gelehrte Organisationsformen zwischen Renaissance und Revolution, hrsg. von $K$. Garber, H. Wismann (Tübingen 1996) 112-167.

${ }_{96} M$. Weber, Die protestantische Ethik und der Geist des Kapitalismus I. Das Problem, in: Archiv für Sozialwissenschaft und Sozialpolitik 20 (1904) 1-54; ders., Die Berufsidee des asketischen Protestantismus, in: ebd. 21 (1905) 1-110; E. Troeltsch, Die Soziallehren der christlichen Kirchen und Gruppen (Heidelberg 1912); G. Becker, Neuzeitliche Subjektivität und Religiosität. Die religionspsychologische Bedeutung von Herauskunft und Wesen der Neuzeit im Denken von Ernst Troeltsch (Regensburg 1982); S. Kalberg, Max Webers Typen der Rationalität: Grundsteine für die Analyse von Rationalisierungsprozessen in der Geschichte, in: Max Weber und die Rationalisierung sozialen Handelns, hrsg. von W. M. Sprondel, C. Seyfarth (Stuttgart 1981) 9-38; L. Kaelber, Webers Lacuna: Medieval Religion and the Roots of Rationalization, in: Journal of the History of Ideas 57 (1956) 465-485; Ernst Troeltschs Soziallehren. Studien zu ihrer Interpretation, hrsg. von $F$. W. Graf, T. Rendtorf (Troeltsch-Studien 6, Gütersloh 1973); O. G. Oexle, Kulturwissenschaftliche Reflexionen über soziale Gruppen in der mittelalterlichen Gesellschaft: Tönnies, Simmel, Durkheim und Max Weber, in: Die Okzidentale Stadt nach Max Weber. Zum Problem der Zugehörigkeit in Antike und Mittelalter, hrsg. von Cbr. Meier (München 1994) 115-159, speziell 133-135.

97 Vgl. neben der in Anm. 37 genannten Literatur: E. Werner, Stadtluft macht frei. Frühscholastik und bürgerliche Emanzipation in der ersten Hälfte des 12. Jahrhunderts (Sitzungsberichte der Akademie der Wissenschaften Leipzig 118/5, Leipzig 1976).

98 Vgl. neben der in Anm. 96 genannten Literatur: C. Morris, The Discovery of the Individual 1050-1200 (London 1972); H. Bayer, Zur Soziologie des mittelalterlichen Individualisierungsprozesses, in: Archiv für Kulturgeschichte 58 (1976) 115-153; J. F. Benton, Consciousness of Self and Perceptions of Individuality, in: Renaissance and Renewal (wie Anm. 17), 263-295; G. Penco, Senso dell'uomo e scoperta dell'individuo nel monachesimo dei secoli XI e XII, in: Benedictina 37 (1990) 285-315.

99 Vgl. Anm. 11-13. 
durch die Reformation erhebliche Rückschläge hat hinnehmen müssen, aber dennoch in den zum Schauplatz der kirchlichen Erneuerung und Gegenreformation gewordenen Regionen mit Unterstützung der neuen Orden des 16. Jahrhunderts eine bemerkenswerte Neublüte erlebte, an der wie im Mittelalter die Frauen einen erheblichen Anteil hatten ${ }^{100}$. Ungeachtet dieser Feststellungen wird man der älteren Forschung, die glaubte, einen unmittelbaren Zusammenhang zwischen semireligiosem Frömmigkeitsstil und Organisationsmodell und den von den Reformatoren vertretenen Vorstellungen vom Gemeindeleben und der Kirchenordnung konstatieren zu können, insofern zustimmen können, daß Übereinstimmungen zwischen dem Kirchenverständnis solcher laici religiosi wie Peter Dieburg und den frühneuzeitlichen Reformatoren unübersehbar sind.

Die seit einigen Jahrzehnten zu beobachtende Konzentration der Forschung auf die nichtregulierten geistlichen Lebensformen des Mittelalters kann den Eindruck erwecken, es habe sich bei ihnen lediglich um ein Epiphänomen des vom frühchristlichen Asketentum bis zur Ausbildung des Ordenswesens führenden Prozesses der Regulierung und Institutionalisierung der vita religiosa gehandelt,

100 M. Benard, La crise des confréries en France au XVIe siècle, in: Population et cultures. Etudes réunies en l'honeur de François Lebrun (Rennes 1989) 397-404. Vgl. auch: ders., Volksfrömmigkeit und Konfessionalisierung, in: Die Katholische Konfessionalisierung. Wissenschaftliches Symposion der Gesellschaft zur Herausgabe des Corpus Catholicorum und des Vereins für Refomationsgeschichte 1923, hrsg. von W. Reinhard, H. Schilling (Schriften des Vereins für Reformationsgeschichte 198, Gütersloh 1995) 258-270; $R$. R. Harding, The Mobilization of Confraternities against the Reformation in France, in: Sixteenth Century Journal 11 (1980) 85-107; B. Montages, Huguenots contre pénitents à Marseille au XVIe siècle, in: Les confréries de pénitents: Dauphine-Provence (Valence 1980) 35-54; K. Norberg, The Counter-Reformation and Women. Religions and Laity, in: Catholicism in Early Modern History, hrsg. von J. W. O'Malley (Reformation Guides to Research 28, St. Louis 1988) 133-146; E. Theissing, Over Klopjes en Kwelzels (Utrecht 1935); E. Schulte van Kessel, Geest en vlees in godsdienst en wetenshap. Vijf opstellen over gezagsconflicten in de 17 de eeuw (Den Haag 1980); F. Koorn, Women without Vows. The Case of the Beguines and the Sisters of the Common Life in the Northern Netherlands, in: Women and Men in Spiritual Culture. XIV-XVII Centuries, hrsg. von E. Schulte van Kessel (Den Haag 1986) 135-147; E. Rapley, The Dévotes. Women and Church in Seventeenth Century France (McGill/Queen's studies in the history of religion 4, Montreal 1990); A. Conrad, Zwischen Kloster und Welt. Ursulinen und Jesuitinnen in der katholischen Reformbewegung des 16./17. Jahrhunderts (Veröffentlichungen des Instituts für Europäische Geschichte Mainz. Abt. Religionsgeschichte 142, Mainz 1991); Dies., Ursulinen und Jesuiten. Formen der Symbiose von weltlichem und männlichem Semireligiosentum in der frühen Neuzeit, in: Doppelklöster und andere Formen der Symbiose männlicher und weiblicher Religiosen im Mittelalter, hrsg. von K. Elm, M. Parisse (Berliner Historische Studien 18, Ordensstudien VIII, Berlin 1992) 213-238; M. Monteiro, Den middelen staet. Waarom vrouwen in de vroegmoderne tijd kozen voor een semireligieus bestaan, in: De dynamiek van religie en cultuur. Geschiedenis van het Nederlands katholicisme, hrsg. von M. Monteiro u.a. (Kempen 1993) 138-161; Dies., Geestelijke maagden. Leven tussen klooster en wereld in Noord-Nederland gedurende de zeventiende eeuw (Hilversum 1996); G. Rocca, Le fondazioni femminili „non religiose“ dopo Trento, in: Congregazioni laici femminili e promozione della donna in Italia nei secoli XVI e XVII, hrsg. von C. Paolocci (Quaderni franzoniani 8,2, Genua 1995) 55-59; A. K. de Meijer, Augustinian Filiae spirituales in Amsterdam during the Seventeenth Century, in: Analecta Augustiniana 60 (1997) 51-80. 
womit sich erklären ließe, warum diese Lebensform im Westen marginalisiert und von den Reformatoren mitsamt dem Ordenswesen in Frage gestellt werden konnte, während sie in der Orthodoxie und den morgenländischen Kirchen, deren Mönchswesen sich der Zentralisierung weitgehend entzogen hat, von größerer Bedeutung blieb ${ }^{101}$. Daß diese Einschätzung mit den historischen Gegebenheiten keineswegs in völliger Übereinstimmung steht, macht der Rekurs auf die Frühzeit des Christentums deutlich. Auch wenn man davon ausgeht, daß es sich bei dem in Spätantike und Mittelalter ausbildenden Kloster- und Ordenswesen und die Ausformung von in den Evangelien formulierten Konzepten geistlicher Lebensgestaltung handelt, ist nicht zu übersehen, daß die als Semireligiosentum bezeichneten vielfältigen Formen nichtregulierter Askese in einen Traditionszusammenhang gehören, der vor die Entstehung des Mönchtums, d.h. bis in die Frühzeit der christlichen Gemeindebildung, zurückgeht ${ }^{102}$.

Die Verteidiger der vita communis der Fraterherren haben denn auch vornehmlich mit dem Hinweis auf die apostolischen Ursprünge ihrer Lebensweise den status medius zu rechtfertigen versucht ${ }^{103}$. Mit dem gleichen Argument ließen sich die Reformatoren trotz ihrer grundsätzlichen Ablehnung des auf Regel und Gelübden beruhenden Ordenslebens dazu veranlassen, die Existenz bzw. Neugründung nichtregulierter religioser Gemeinschaften zu dulden ${ }^{104}$. Ja, selbst im Kirchenrecht hat sich die Einsicht durchgesetzt, daß es sich beim Semireligiosentum keineswegs um ein dem Ordenswesen nach Alter und Wirksamkeit nachgeordnetes Phänomen handelt, das nur für das Mittelalter von Bedeutung gewesen sei105. Die Feststellung, daß es sich bei den mit dem abwertend klingenden Sammelbegriff „Semireligiosentum “ bezeichneten Lebensformen um eine bis in die Anfänge des Christentums zurückgehende sowohl in allen Epochen der Kirchengeschichte als auch in den meisten christlichen Kirchen zu beobachtende Erscheinung han-

$101 \mathrm{Vgl}$. u.a. T. Miller, The Birth of the Hospital in the Byzantine Empire (Baltimore, London 1985); G. Dragon, „Ainsi rien n'échappera à la réglementation“. Etat, corporation, confréries, in: Hommes et richesses dans l'Empire byzantin, hrsg. von V. Kravaki, J. Lefort, C. Morrisson (Paris 1991) II, 155-182.

102 H. v. Campenhausen, Die Askese im Urchristentum (Tübingen 1949); P. Brown, The Body and Society. Men, Women, and Sexual Renounciation in Early Christianity (New York 1988); S. Elm, Virgins of God. The Making of Asceticism in Late Antiquity (Oxford [21996]). 103 U. Hinz, Die nordwestdeutschen Brüder vom Gemeinsamen Leben in der zweiten Hälfte des 16. Jahrhunderts. Zur Konfrontation mit der katholischen Konfessionalisierung, in: Ons geestelijk Erf 69 (1995) 157-174; ders., Die Brüder vom Gemeinsamen Leben im Jahrhundert der Reformation. Das Münstersche Kolloquium (Spätmittelalter und Reformation. Neue Reihe 9, Tübingen 1997).

104 G. Krause, R. Stupperich, Bruderschaften, Schwesternschaften, Kommunitäten, in: Theologische Realenzyklopädie VII (1981) 195-212; C. Joest, Spiritualität evangelischer Kommunitäten. Altkirchlich-monastische Traditionen in evangelischen Kommunitäten von heute (Göttingen 1995).

105 Neben der in den Anm. 11 und 14 genannten Lit. vgl. auch: M. Schlosser, Alt - aber nicht veraltet. Die Jungfrauenweihe als Weg der Christusnachfolge, in: Ordenskorrespondenz 33 (1992) 41-64, 165-178, 289-311; dies., Solus cum solo - Eremiten gestern und heute. Zu CIC 1983 Titel I, c. 603, in: ebd. 37 (1996) 188-212. 
delt, kann nicht ohne Folgen für die Einschätzung ihrer historischen Funktion bleiben. Sie zwingt dazu, nicht nur das Verhältnis von Ordenswesen und nichtregulierten geistlichen Gemeinschaften und Lebensformen in einem anderen Licht als zuvor zu sehen, sondern auch die Rolle, die die Vita regularis sine regula in Spätmittelalter und früher Neuzeit spielte, in einen breiteren Kontext als bisher zu stellen. Sie darf nicht isoliert und erst recht nicht allein unter dem Aspekt der Reformation, Konfessionalisierung und den ihnen folgenden gesellschaftlichen und geistigen „Modernisierungsvorgängen“ gesehen werden, sondern muß in erster Linie als das beurteilt werden, als was sie sich im Rückblick auf ihre Anfänge und Geschichte darstellt: nämlich als eine bis in die Frühzeit des Christentums zurückgehende Lebensform von Individuen und Gemeinschaften, die sowohl Kritik und Widerspruch als auch Neubeginn und Rückbesinnung immer dann ermöglichte, wenn hergebrachte Wertvorstellungen und etablierte Institutionen an Überzeugungskraft und Autorität verloren, und daher nicht nur im Spätmittelalter und im Zeitalter der Reformation und Gegenreformation, sondern auch früher und später in Übergangs- und Krisenzeiten besondere Bedeutung erlangte. 